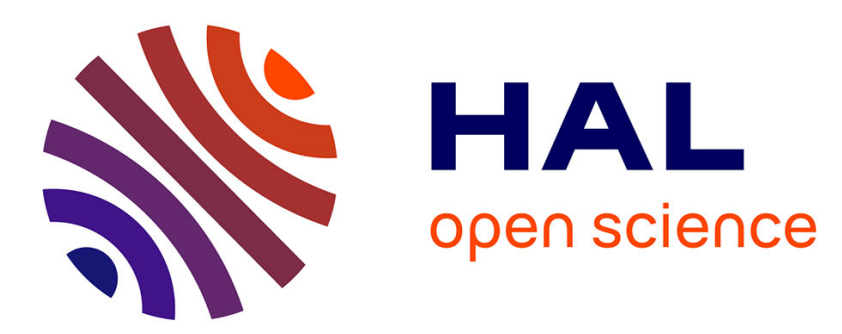

\title{
Combining LES of combustion chamber and an actuator disk theory to predict combustion noise in a helicopter engine
}

\author{
Thomas Livebardon, Stéphane Moreau, Laurent Y.M. Gicquel, Thierry \\ Poinsot, Eric Bouty
}

\section{To cite this version:}

Thomas Livebardon, Stéphane Moreau, Laurent Y.M. Gicquel, Thierry Poinsot, Eric Bouty. Combining LES of combustion chamber and an actuator disk theory to predict combustion noise in a helicopter engine. Combustion and Flame, 2016, 165, pp.272-287. 10.1016/j.combustflame.2015.12.012 . hal-01302512

\section{HAL Id: hal-01302512 \\ https://hal.science/hal-01302512}

Submitted on 14 Apr 2016

HAL is a multi-disciplinary open access archive for the deposit and dissemination of scientific research documents, whether they are published or not. The documents may come from teaching and research institutions in France or abroad, or from public or private research centers.
L'archive ouverte pluridisciplinaire HAL, est destinée au dépôt et à la diffusion de documents scientifiques de niveau recherche, publiés ou non, émanant des établissements d'enseignement et de recherche français ou étrangers, des laboratoires publics ou privés. 


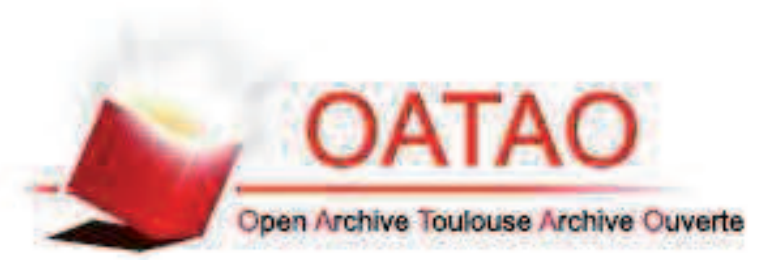

\section{Open Archive TOULOUSE Archive Ouverte (OATAO)}

OATAO is an open access repository that collects the work of Toulouse researchers and makes it freely available over the web where possible.

This is an author-deposited version published in : http://oatao.univ-toulouse.fr/ Eprints ID : 15668

To link to this article : DOI:10.1016/j.combustflame.2015.12.012 URL : http://dx.doi.org/10.1016/j.combustflame.2015.12.012

\section{To cite this version :}

Livebardon, Thomas and Moreau, Stéphane and Gicquel, Laurent Y.M. and Poinsot, Thierry and Bouty, Eric Combining LES of combustion chamber and an actuator disk theory to predict combustion noise in a helicopter engine. (2016) Combustion and Flame, vol. 165. pp. 272-287. ISSN 0010-2180

Any correspondence concerning this service should be sent to the repository administrator: staff-oatao@,listes-diff.inp-toulouse.fr 


\title{
Combining LES of combustion chamber and an actuator disk theory to predict combustion noise in a helicopter engine
}

\author{
Thomas Livebardon $^{\mathrm{a}, *}$, Stéphane Moreau ${ }^{\mathrm{b}}$, Laurent Gicquel ${ }^{\mathrm{c}}$, Thierry Poinsot ${ }^{\mathrm{d}}$, Eric Bouty \\ a CERFACS, Toulouse 31057, France \\ ' Université de Sherbrooke, Sherbrooke, QC J1K 2R1, Canada \\ ${ }^{\text {c } C E R F A C S, \text { Toulouse 31057, France }}$ \\ ${ }^{\mathrm{d}}$ Institut de Mécanique des Fluides de Toulouse, Toulouse 31400, France \\ e Turbomeca S.A., Bordes 64511, France
}

Keywords:

Combustion noise

Acoustics

Large Eddy Simulations

\begin{abstract}
A B S T R A C T
A method to predict combustion noise in real aero-engines using Large Eddy Simulations (LES) of the combustion chamber coupled with an analytical approach to model the acoustic transmission of acoustic and entropy noise through the turbine stages is described. The proposed strategy is tested by comparing predictions of the computed noise with experimental results obtained for a full helicopter engine with high frequency pressure sensors located in the chamber and in all turbine stages. First, an extensive experimental database is used to localize the acoustic sources responsible for the "core-noise" by a three-sensor technique constituting the reference data against which predictions will be assessed. Second, LES of the combustion chamber for two representative operating points are achieved and discussed. The waves leaving the combustion chamber are extracted from these simulations at the outlet of the chamber, and an analytical method based on actuator disk theory and compact assumptions gives noise levels at the various turbine stages using the waves amplitudes at the chamber outlet. Excellent agreement is found at low frequencies between simulations and engine measurements. These results also confirm the importance of indirect combustion noise (due to entropy waves) generated in a helicopter turboshaft engine for the first time.
\end{abstract}

\section{Introduction}

Dwindling oil reserves and ACARE 2050 targets on noise and pollution challenge aerospace industry to design increasingly efficient and silent aero-engines. To meet such new challenges, turbulent and lean partially premixed combustion has emerged in recent aeronautical engine combustion chambers but it triggers unwanted effects such as thermo-acoustic instabilities and noise generation. For several decades, combustion noise has been known as a major contributor to the broadband noise generated by aircraft engines also called "core noise". Current understanding decomposes combustion noise into two main noise sources:

- Direct combustion noise corresponds to the generation of acoustic waves by turbulent combustion within the chamber.

- Indirect noise is the generation of downstream and upstream acoustic waves due to the acceleration of temperature inhomogeneities propagating through the turbine stages.

\footnotetext{
* Corresponding author.

E-mail address: livebard@cerfacs.fr (T. Livebardon).
}

Indirect noise mechanisms were first described in [1-3], where one way coupling mechanisms between entropy spots and acoustic waves due to a velocity gradient in a quasi-one-dimensional nozzle was established. Using a compact assumption (characteristic length of the nozzle being negligible compared with the wavelength of the low-frequency combustion noise), linearized jump relations linking entropy and acoustic fluctuations are written through the nozzle. More recently, different analytical methods have been developed to remove the compact assumption in a quasi-one-dimensional case [4-6], taking into account arbitrary nozzle shapes [7] or shock waves. In the same manner, modeling of combustion-generated noise through turbine stages was addressed by Cumpsty and Marble [8] or Pickett [9], using the compact assumption and conservation laws between downstream and upstream sections of a turbine row. The low-frequency nature of combustion noise allowed considering only two-dimensional waves with no radial component. Thanks to this two-dimensional description, azimuthal modes, as well as flow deviation, could be considered. In practice, all these analytical methods and models must be validated using either numerical simulations or experimental databases. 


\begin{tabular}{|c|c|}
\hline \multicolumn{2}{|c|}{ Nomenclature } \\
\hline$A$ & characteristic tube section \\
\hline$c$ & mean local speed of sound \\
\hline$c_{p}$ & specific heat at constant pressure \\
\hline G & cross-spectrum \\
\hline$h$ & enthalpy \\
\hline$H$ & linear transfer function \\
\hline I & rothalpy \\
\hline$k$ & wave number \\
\hline$k_{x}$ & axial wave number \\
\hline K & dimensionless wave number magnitude \\
\hline $\mathbf{K}$ & transfer matrix \\
\hline$L_{p}$ & characteristic tube length \\
\hline$l_{c}^{p}$ & axial chord length \\
\hline$L_{i}$ & axial distance between rows \\
\hline$M$ & Mach number \\
\hline$\dot{m}$ & mass flow rate \\
\hline$N_{S}$ & number of turbine blade rows \\
\hline$N$ & uncorrelated noise in the frequency domain \\
\hline$p$ & pressure \\
\hline $\operatorname{Pr}$ & Prandtl number \\
\hline$r$ & specific gas constant \\
\hline $\mathcal{R}$ & radius \\
\hline$s$ & entropy \\
\hline$S$ & signal emitted by a source in the frequency domain \\
\hline $\mathbf{S}$ & phase-shift transfer matrix \\
\hline$T$ & temperature \\
\hline $\mathbf{T}$ & transfer matrix of a blade row in a waveform \\
\hline$U$ & rotational velocity \\
\hline$v$ & absolute azimuthal velocity \\
\hline$w$ & absolute velocity magnitude \\
\hline $\mathrm{w}$ & wave \\
\hline$\hat{\mathrm{W}}$ & filtered wave \\
\hline W & noise signal in the frequency domain \\
\hline $\mathbf{W}$ & wave vector \\
\hline$x$ & axial component \\
\hline$X$ & experimental signal in the frequency domain \\
\hline$\alpha$ & azimuthal coordinate \\
\hline$\rho$ & density \\
\hline$\gamma$ & ratio of specific heats \\
\hline$\epsilon$ & $\begin{array}{l}\text { transfer matrix of a blade row for primitive vari- } \\
\text { ables }\end{array}$ \\
\hline$\eta$ & indirect to direct noise ratio \\
\hline$\omega$ & pulsation \\
\hline$\theta$ & flow deviation \\
\hline$v$ & kinematic viscosity \\
\hline$v$ & wave front angle \\
\hline$\lambda$ & wavelength \\
\hline$\Omega$ & ratio of wavelength to axial blade chord \\
\hline$\zeta$ & $\begin{array}{l}\text { dimensionless difference between total enthalpy } \\
\text { and rothalpy within a blade row }\end{array}$ \\
\hline$t$ & total state \\
\hline$u$ & upstream \\
\hline$d$ & downstream \\
\hline & fluctuation \\
\hline+ & upstream \\
\hline- & downstream \\
\hline$D L R$ & Deutsches Zentrum für Luft-und Raumfahrt \\
\hline LES & Large Eddy Simulations \\
\hline NASA & National Aeronautics and Space Administration \\
\hline$P S D$ & power spectral density \\
\hline
\end{tabular}

In realistic aeronautical engines, measurements of core-noise are a challenge because of the harsh conditions found in combustion chambers and turbines stages. In this context, analytical models for acoustic generation-transmission in turbines were primarily based on a database provided by NASA [10]. Recently, in the Seventh European Framework of Programme for research, the Turboshaft Engine Exhaust Noise Identification (TEENI) project was dedicated to the location of acoustic sources in a realistic helicopter engine covering the entire downstream section of a real engine from the combustion chamber to the exhaust with an identification of sources in a radiated acoustic field issued by real operating conditions. To this end, TEENI partners developed sets of sensors for measuring and analyzing unsteady quantities in a fullscale engine.

Currently, numerical simulations are potential alternatives to real test cases. Large-Eddy Simulation (LES) techniques, coupled with the increase of computing power, are mature methods to provide accurate compressible simulations of complex reacting turbulent flows. They have been successfully validated on academic and realistic burners, to retrieve mean statistical features, but also unsteady flow characteristics [11-15]. More precisely, LES is able to capture the strong interactions between turbulent structures and flames, which lead to acoustic wave generation. As such, it was used to study combustion instabilities within industrial and academic burners [16,17], demonstrating the efficiency of LES for combustion-generated noise. With such tools, Leyko [18] used an actuator disk theory [8] coupled with a LES of a turbulent reactive flow in an aero-engine to compute core-noise induced by a combustion chamber. Using also numerical simulations of a twodimensional turbine stage, Leyko proved the ability of this analytical method to predict indirect combustion noise generated by entropy fluctuations, the direct combustion noise generated through a stator [18] or a rotor [19] and through a complete turbine stage [6]. In the same way, this actuator disk theory is investigated by comparing two-dimensional numerical simulations of a subsonic stator with an injection of entropy spots against analytical predictions [20] showing the validity of this theory for low-frequency cut-on acoustic modes. Indirect noise has been thoroughly studied by DLR in an experiment called Entropy Wave Generator [21,22] which has also been computed by many groups [23-25]. This experiment, however, is a single nozzle and misses many features of real engines so that, to date no actual industrial configuration has been tackled numerically or theoretically to assess the importance of combustion noise. In a first attempt to fill in this gap, the current study presents the TEENI data and a numerical tool to predict noise generated by a real helicopter engine. A complete description of the TEENI experimental setup and main results are presented in Section 2. Section 3 describes the hybrid method called CONOCHAIN coupling LES and analytical approach. LES results are detailed in Section 4.1. Finally, Section 4.2 discusses the validation of the CONOCHAIN tool by comparing predictions with full-scale test results.

\section{TEENI: a full-scale experimental test}

\subsection{Experimental setup}

The experimental system is a fully instrumented helicopter engine shown in Fig. 1. The harsh conditions, in terms of temperature and pressure especially in the combustion chamber, required dedicated original probe designs, developed by DLR (Berlin). Each pressure probe is a flush-mounted pin-hole apparatus with a remote microphone put perpendicular to a semi-infinite tube to limit standing wave effects [26]. To protect the microphone from hot combustion products, a cooling system injects a controlled air flow rate through the tube [27]. Temperature sensors are based on a 


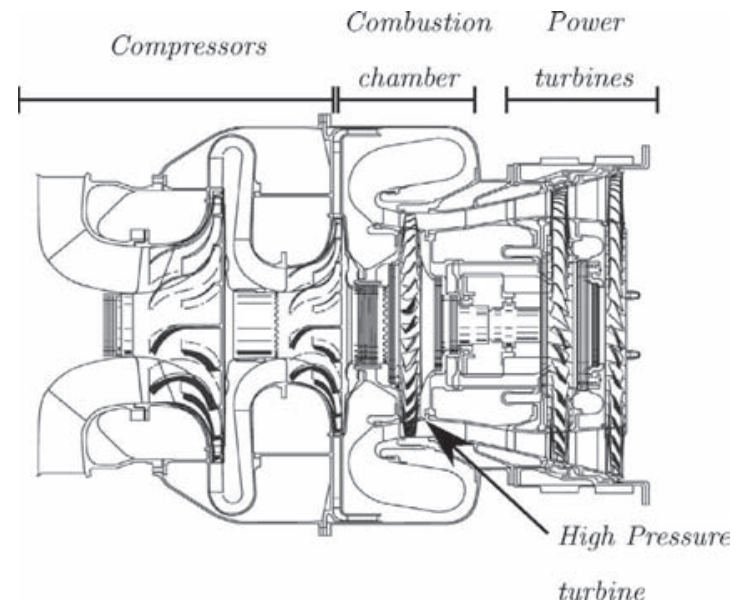

Fig. 1. Schematic of the real TEENI turboshaft engine.

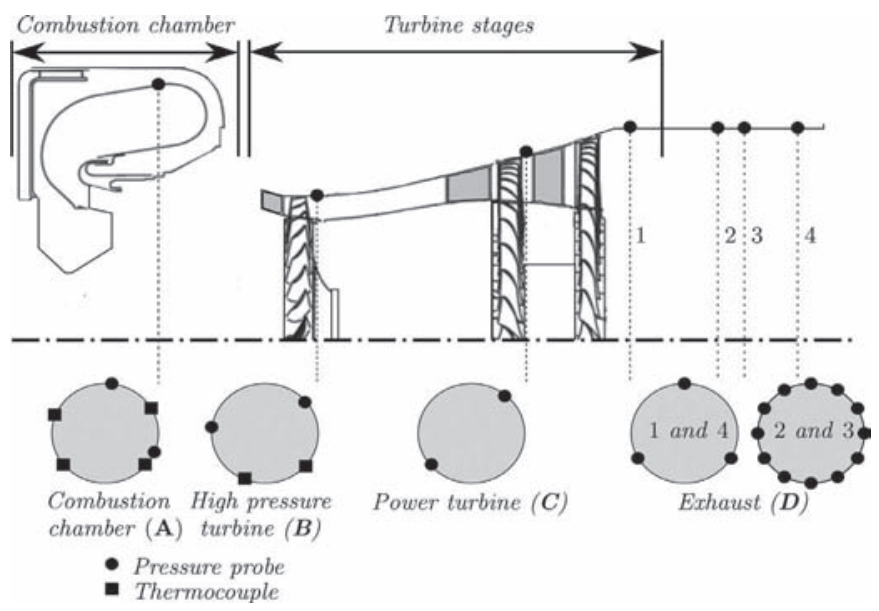

Fig. 2. Sketch of TEENI experimental setup and location of unsteady pressure and temperature probes.

twin thermocouple designed to be able to detect fluctuations up to $700 \mathrm{~Hz}$.

To measure pressure and temperature fluctuations in each module of the engine from the combustor to the exhaust, several probes are mounted at different circumferential locations (Fig. 2):

- 2 pressure probes and 4 twin thermocouples are located in the combustion chamber (position $\mathbf{A}$ in Fig. 2 ).

- 2 pressure probes and 2 twin thermocouples are placed between the high-pressure turbine (HPT) and the power turbine (position B in Fig. 2).

- 2 pressure probes located between the first and the second turbine stages of the power turbine (position $\mathbf{C}$ in Fig. 2).

- 30 pressure probes are present in an extended nozzle: 2 planes with 3 probes and 2 planes with 12 probes (position D in Fig. 2).

For proper calibration, a complex transfer function is computed at ambient conditions for each remote pressure probe up to $4000 \mathrm{~Hz}$ [26]. The in-situ calibration has been achieved with a B\&K Type- 4228 pistonphone for each pressure probe without any cross-flow present but with the cooling tubes attached. Pressure fluctuations in the engine are recorded with a sampling frequency of $25.6 \mathrm{kHz}$ whereas unsteady temperatures are recorded with a sampling frequency of $102.4 \mathrm{kHz}$. Unfortunately, the twin thermocouples failed to provide reliable temperature fluctuations within the combustion chamber and the high-pressurized turbine. Data acquisition is performed at 7 different operating points from the
Table 1

Dimensionless combustion parameters at low and high powers.

\begin{tabular}{lll}
\hline Dimensionless combustion parameters & \multicolumn{2}{l}{ Operating points } \\
\cline { 2 - 3 } & Low & High \\
\hline Engine power & $310 \mathrm{~kW}$ & $900 \mathrm{~kW}$ \\
Stagnation temperature & 0.8 & 1 \\
Stagnation pressure & 0.66 & 1 \\
Fuel-air ratio & 0.78 & 1 \\
Mass flow rate & $2.20 \mathrm{~kg} / \mathrm{s}$ & $3.25 \mathrm{~kg} / \mathrm{s}$ \\
\hline
\end{tabular}

lowest power setting encountered in flight conditions to take-off power. Measurements are performed at stabilized operating points after a transitional phase to reach the engine thermal equilibrium.

In this paper, only results relative to two operating points, at the lowest and highest powers, are presented. The combustion chamber parameters are detailed in Table 1 . The dimensionless parameters are referenced to the high-power settings.

\subsection{Signal processing and experimental data exploitation}

\subsubsection{Power spectral density of pressure fluctuations}

Power spectral densities (PSD) of pressure fluctuations at each location within the engine (Fig. 2) are given in Fig. 3 for low and high power. In the combustion chamber, the acoustic activity is very similar for both power settings, exhibiting narrowband ( $\Delta f$ $=140 \mathrm{~Hz})$ as well as broadband $(\Delta f=1200 \mathrm{~Hz})$ modulations (Fig. 3(a)). Both modulation patterns were identified: they correspond to acoustic resonances within the sensors, where the kinematic viscosity decreases with pressure and leads to weak acoustic damping. As the combustion chamber pressure is the highest within the engine, these resonances in the PSD of pressure fluctuations are mostly seen at station $\mathbf{A}$ (Fig. 3(a)). Details of an acoustic modeling of the pressure probes used in the experiment are provided in the appendix.

Figure 3 (b) focuses on the high pressure turbine PSD levels. A difference of $5 \mathrm{~dB}$ is noted over the whole spectra obtained for the two operating points with a broadband hump up to $1500 \mathrm{~Hz}$. Similarly to the combustion chamber, acoustic resonances are also visible in this section of the engine. Tonal peaks generated by the rotating shafts are also present in both plots (although more pronounced in the HPT Fig. 3(b), the frequency shift between peaks being induced by the difference in rotating shaft speeds of the two operating conditions. These peaks are also visible in the power turbine PSD in Fig 3(c), the difference between the two operating conditions being in the order of $2 \mathrm{~dB}$. The PSD at the exhaust in Fig 3(d), shows a $5 \mathrm{~dB}$ difference from $500 \mathrm{~Hz}$ to $4000 \mathrm{~Hz}$, identical acoustic levels being recorded below $500 \mathrm{~Hz}$.

\subsubsection{Three-sensor technique}

Due to the broadband nature of combustion noise, characterization of its contribution in the core noise requires broadband-noise breakdown techniques. Indeed, each signal $X$ results from a signal emitted by a source $S$ through a linear transfer function $H$ and an added uncorrelated noise $N$. In frequency domain, $X$ is equal to $H \cdot S+N$. In the scope of combustion noise, the aim is to identify the acoustic power produced within the engine correlated with the acoustic power radiated at the outlet. The first way is to compute coherence spectra between any pressure probe signal in the engine and an exhaust sensor signal. Yet, this method does not yield significant coherence levels, the correlation being lost because of the high uncorrelated turbulent levels at the exhaust. To enhance the signal-to-noise ratio, a technique based on averaged cross-spectra between three sensors is applied [28-31]. Its objective is to obtain the coherent power emitted by an acoustic source $S$ within the engine without contributions of uncorrelated noise and radiated at 


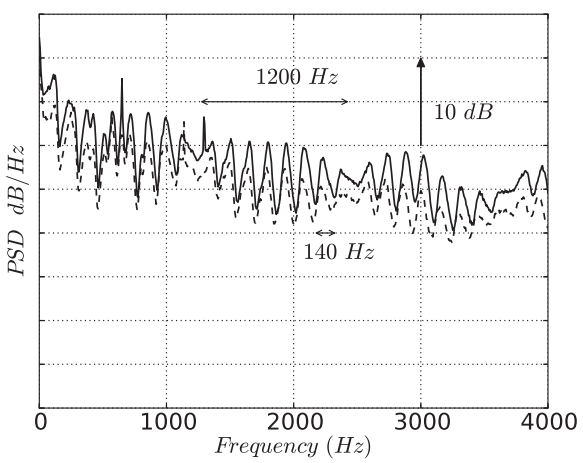

(a) Combustion Chamber (A)

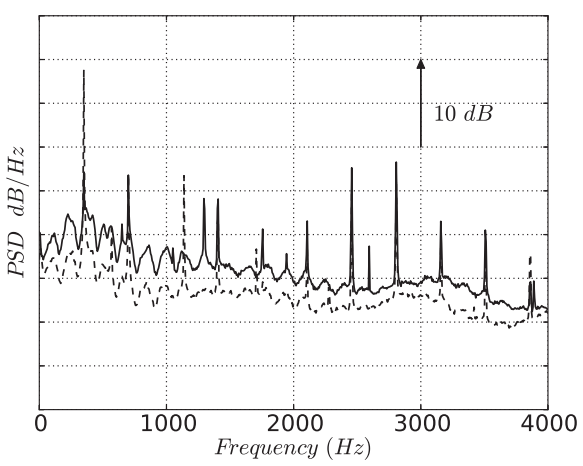

(c) Power turbine $(\mathbf{C})$

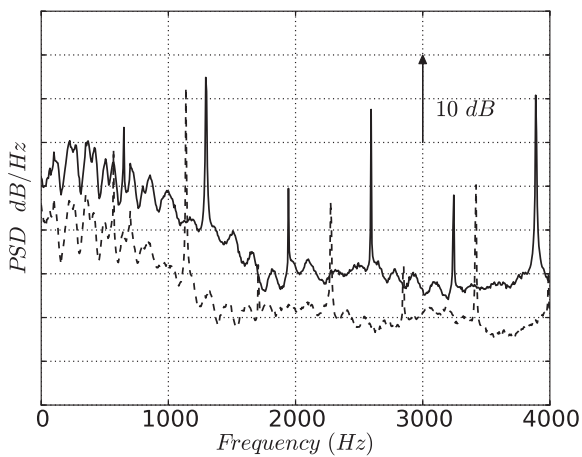

(b) High Pressure Turbine (B)

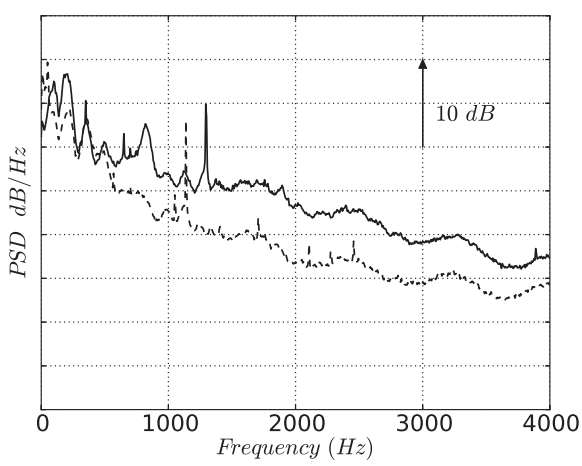

(d) Exhaust (D)

Fig. 3. PSD of pressure fluctuations at maximum power (__ $)$ and minimum power measured (- - - ) in different locations within the engine.

the exhaust. From the combustion chamber to the power turbines at each location defined in Fig. 2, the two pressure probes (noted with the subscripts 1 and 2, respectively) are combined with a reference probe at the exhaust (noted with the subscript 3). Averaged cross-spectra between these signals are

$G_{12}=H_{1} \cdot H_{2}^{*} \cdot S \cdot S^{*}$,

$G_{23}=H_{2} \cdot H_{3}^{*} \cdot S \cdot S^{*}$

$G_{31}=H_{3} \cdot H_{1}^{*} \cdot S \cdot S^{*}$

Note that these cross-spectra are not impacted by power provided by uncorrelated noise. The coherent power of the source $S$ can thus be recovered and follows for the exhaust probe

$G_{S 3}=\frac{G_{23} \cdot G_{31}}{G_{12}}=H_{3} \cdot H_{3}^{*} \cdot S \cdot S^{*}$.

Finally, applying the three-sensor technique between an exhaust pressure probe and each pair of probes located either in the combustion chamber or in the high pressure turbine or in the power turbine, localization of broadband noise generation radiated in the exhaust is available. Using this method for probes located in the combustion chamber yields a narrow-band coherent PSD close to $200 \mathrm{~Hz}$ as evidenced in Fig. 4 for both operating points. On the contrary, this technique shows a global increase of coherent PSD in the range $[200 \mathrm{~Hz}, 1000 \mathrm{~Hz}$ ] in Fig. 5, which is emphasized at the high power setting. Furthermore, no change is detected in the generation of added coherent PSD in $[0 \mathrm{~Hz}, 4000 \mathrm{~Hz}]$ in the power turbine compared with the high pressure turbine as seen in Fig. 6. However, cross-correlations between pressure fluctuations at any location in the whole engine or unsteady temperature measured by twin-thermocouples in the combustion chamber and the highpressure turbine did not provide any noticeable results to directly conclude on acoustic waves generated by entropy spots. In summary, the three-sensor technique reveals a significant narrow direct combustion noise component around $200 \mathrm{~Hz}$ generated in the combustion chamber, and a broadband hump up to $1500 \mathrm{~Hz}$ attributed to broadband noise generated by the HPT which could be indirect combustion noise.

\section{Combustion noise prediction: CONOCHAIN methodology}

The full simulation of core noise and its propagation through the turbine stages is currently out of reach in terms of computational cost. However, in order to predict combustion noise generation, LES is a necessary tool to correctly predict entropy, vorticity and acoustic waves generated by the turbulent combustion process. This step is highlighted in Section 3.1. As combustion noise is low frequency and therefore corresponds to wavelengths much larger than the blade chords and heights, acoustic generation and propagation through turbine stages can be described with a twodimensional compact actuator disk theory dealt with Section 3.2. This analytical method is termed CHORUS. The combination of LES simulations and CHORUS is the CONOCHAIN methodology (Fig. 7). Flow variables are extracted from LES at several planes perpendicular to the engine axis at the exit of the combustion chamber (planes $\mathbf{P}$ in Fig. 7). They yield the primitive dimensionless fluctuating variables used in Cumpsty and Marble's model [8]:

- entropy $\left(s^{\prime} / C_{p}\right)$

- velocity magnitude $\left(w^{\prime} / c\right)$

- pressure $\left(p^{\prime} \mid \gamma p\right)$

- flow angle $\left(\theta^{\prime}\right)$. 


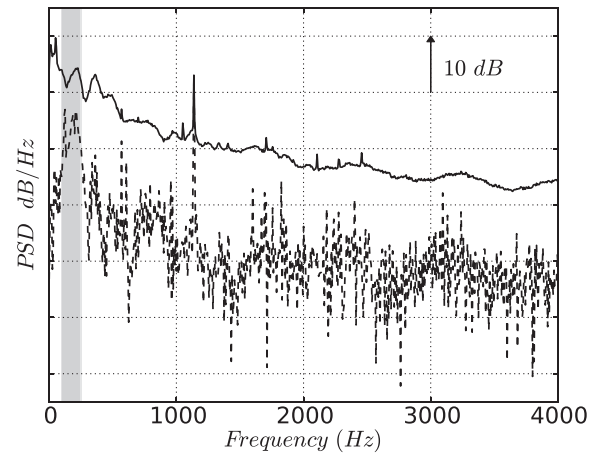

(a) Low Power

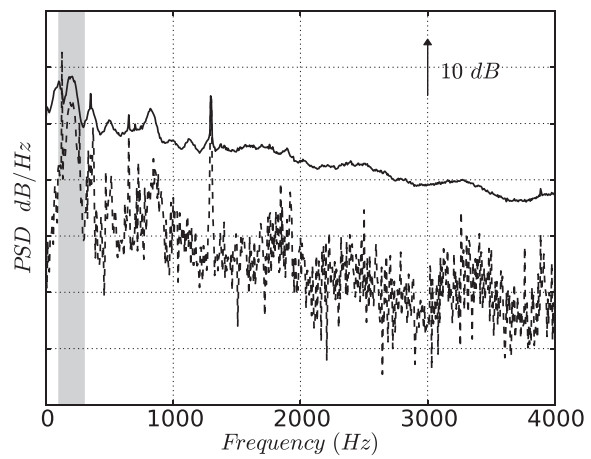

(b) High Power

Fig. 4. PSD of the three-sensor technique applied between the combustion chamber and the exhaust (- - -) and PSD of pressure fluctuations of the reference probe ( $\_$).

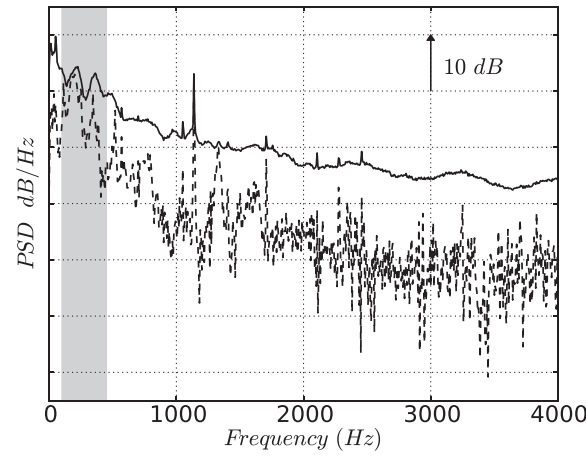

(a) Low Power

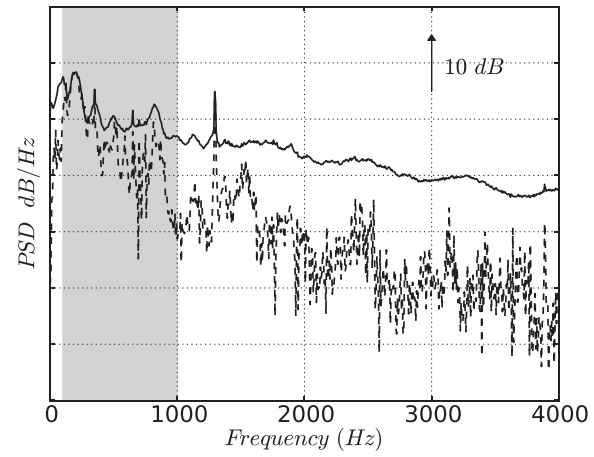

(b) High Power

Fig. 5. PSD of the three-sensor technique applied between the HPT and the exhaust (- - -) and PSD of pressure fluctuations of the reference probe (_

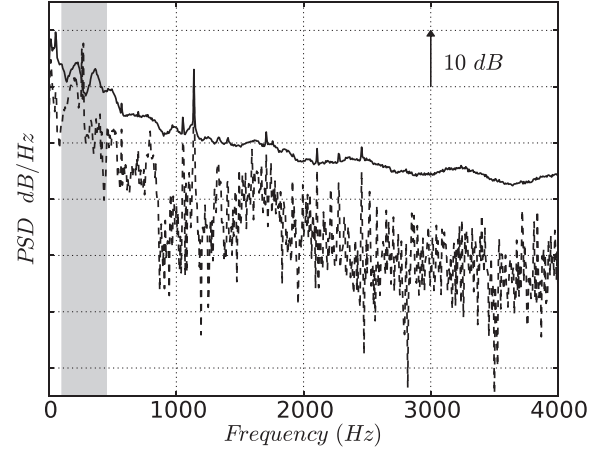

(a) Low Power

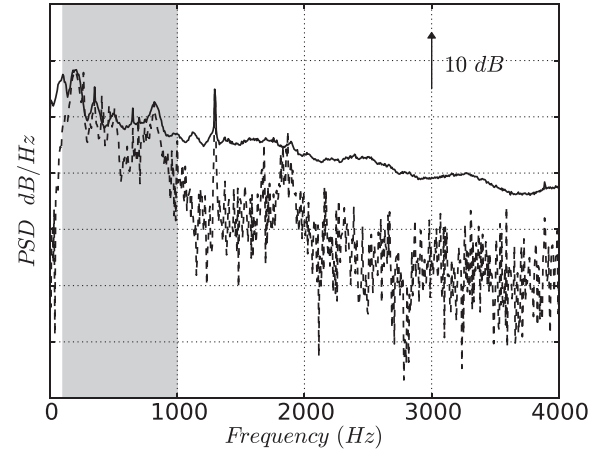

(b) High Power

Fig. 6. PSD of the three-sensor technique applied between the power turbine and the exhaust (- - -) and PSD of pressure fluctuations of the reference probe (_

By assuming time harmonic fluctuations, these primitive variables are combined to build upstream and downstream propagating acoustic waves $\left(\mathrm{w}^{+}\right.$and $\left.\mathrm{w}^{-}\right)$, entropy waves $\left(\mathrm{w}_{S}\right)$ and vorticity waves $\left(\mathbf{w}_{v}\right)$. Thus, each wave is written as follows:

$\mathrm{w}=|\mathrm{w}| \exp \left(i \omega\left(t-\frac{1}{c} K(\cos v+\sin v)\right)\right)$

where $K$ is a dimensionless wave number magnitude and $v$ the wave front angle with respect to the engine axis. The whole process can be summarized by the following steps $[6,18,19]$ :

- Instantaneous LES solutions are interpolated over planes at the outlet of the combustion chamber (typically 500 to 1000 snapshots) as shown in Fig. 7. Primitive variables denoted by $f^{\prime}$ are radially averaged and decomposed using temporal Fourier transform, namely

$\underbrace{f^{\prime}(\mathcal{R}, \alpha, t) \rightarrow \hat{f}^{\prime}(\alpha, t)}_{\text {Radial average }}$

and

$\underbrace{F^{\prime}(\alpha, \omega)=\frac{1}{t_{L E S}} \int_{0}^{t_{L E S}} \hat{f}^{\prime}(\alpha, t) e^{-i \omega t} d t}$

Temporal Fourier transform

where $t_{L E S}$ is the duration of the productive simulation and $F^{\prime}$ is the primitive variable $f^{\prime}$ in the frequency domain. Radial averaging is used to extract the zeroth radial mode from the unsteady fields at the chamber exit. This mode is the only one which can be handled by the two-dimensional actuator disk theory. 


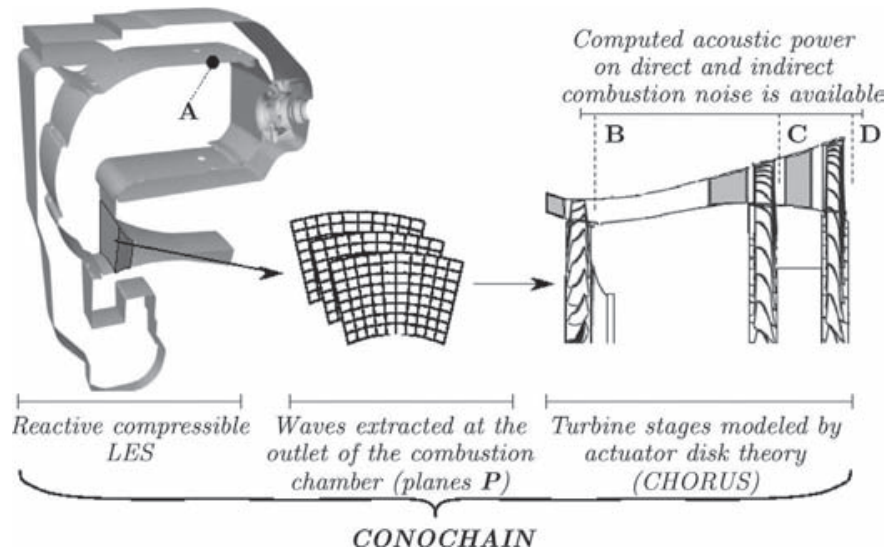

Fig. 7. Sketch of the CONOCHAIN methodology.

Spatial Fourier transform over the azimuthal direction bounded by the angular extrema $\alpha_{\min }$ and $\alpha_{\max }$ then allows performing an azimuthal modal decomposition where $m$ is the azimuthal mode index, namely

$\underbrace{\mathcal{F}^{\prime}(m, \omega)=\frac{1}{\alpha_{\max }-\alpha_{\min }} \int_{\alpha_{\min }}^{\alpha_{\max }} F^{\prime}(\alpha, \omega) e^{-i m \alpha} d \alpha}_{\text {Azimuthal Fourier transform }}$.

Using Eq. (8) and the energy conservation in terms of signal power ensured by Parseval's theorem, the relative contribution of the azimuthal mode $\mathcal{F}^{\prime}(m, \omega)$ is evaluated with

$$
\frac{\mathcal{F}^{\prime}(m, \omega)^{2}}{\frac{1}{\alpha_{\max }-\alpha_{\min }} \int_{\alpha_{\min }}^{\alpha_{\max }} F^{\prime}(\alpha, \omega)^{2} d \alpha}
$$

- Dispersion relations, derived from two-dimensional linearized Euler equations, allow building primitive variables in a waveform

$$
\left(\begin{array}{c}
s^{\prime} / C_{p} \\
w^{\prime} / c \\
p^{\prime} / \gamma p \\
\theta^{\prime}
\end{array}\right)=[\mathbf{K}]\left(\begin{array}{c}
\mathrm{w}_{s} \\
\mathrm{w}_{v} \\
\mathrm{w}_{+} \\
\mathrm{w}_{-}
\end{array}\right)
$$

where the matrix $\mathbf{K}$ is defined as follows:

$$
\left(\begin{array}{cccc}
1 & 0 & 0 & 0 \\
0 & -i \frac{\sin \left(v_{v}-\theta\right)}{K_{v}} & \frac{K_{+} \cos \left(\theta-v_{+}\right)}{1-K_{+} M \cos \left(v_{+}-\theta\right)} & \frac{K_{-} \cos \left(\theta-v_{-}\right)}{1-K_{-} M \cos \left(v_{-}-\theta\right)} \\
0 & 0 & 1 & 1 \\
0 & i \frac{\cos \left(v_{v}-\theta\right)}{K_{v} M} & \frac{K_{+} \sin \left(v_{+}-\theta\right)}{1-K_{+} M \cos \left(v_{+}-\theta\right)} & \frac{K_{-} \sin \left(v_{-}-\theta\right)}{1-K_{-} M \cos \left(v_{-}-\theta\right)}
\end{array}\right) .
$$

- The waves $w$ are filtered at the exit of the combustion chamber using the set of $N_{\text {planes }}$ interpolating planes to extract the propagating components [32], namely

$$
\hat{\mathrm{W}}=\frac{1}{N_{\text {planes }}} \sum_{i=1}^{N_{\text {planes }}} \mathrm{w}_{i} \exp \left(-i K x_{i}\right) \text {. }
$$

- Using this wave decomposition and an extension of the actuator disk theory [8], CHORUS propagates these waves through turbine stages and computes acoustic power attributed to direct and indirect combustion noise at several locations in a real turbine (Fig. 8).

\subsection{LES solver}

Two LES have been performed using the AVBP solver [33]. AVBP runs on massively parallel schemes to solve the compressible reacting Navier-Stokes equations. To limit the computational cost, only one sector is simulated. AVBP uses unstructured grids with

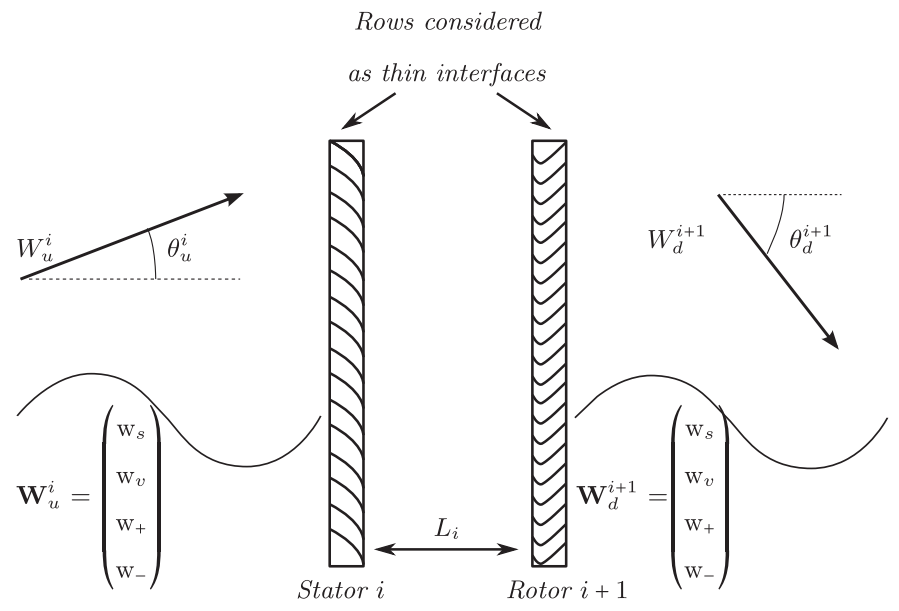

Fig. 8. Sketch of the actuator disk theory applied on turbine stage.

the TTG scheme that has a third order spatial and temporal accuracy [34]. Subgrid scale stresses are described by the Smagorinksy model [35] while the dynamic thickened flame model is used to model the flame/turbulence interactions [36-38]. Kerosene/air chemistry is modeled using a synthetic surrogate coupled with a reduced mechanism involving 6 species and 2 reactions [39]. Reaction rates are modeled by Arrhenius laws [38], where the preexponential constants are fitted in rich regimes to recover proper laminar flame speeds. The unstructured mesh considered in this study contains 12 million tetrahedral elements, the primary zone of the combustor being described with mesh element sizes close to $0.5 \mathrm{~mm}$. Previous numerical simulations of this combustion chamber were performed to investigate the acoustic coupling between the unsteady flame and the system acoustic eigenmodes [17] based on a similar methodology. Since the objective is to compute waves leaving the chamber to enter the turbine, boundary conditions require specific treatments to handle the unsteady flow features. In AVBP, the Navier Stokes Characteristic Boundary Conditions (NSCBC) method is implemented [40,41] decomposing each variation of the flow variables on the boundaries into ingoing and outgoing waves. In these computations, the NSCBC treatment is only applied at the inlet where the mass flow rate and the flow temperature are known, while wall-law adiabatic conditions are imposed at all walls of the chamber. To mimic the choked stator of the high pressure turbine, a nozzle is added at the chamber outlet to keep the curvilinear variation of normal surface through the row. The throat section of the nozzle matches the section of the real HPT stator used experimentally. Since the throat is choked, no additional boundary condition is needed at the chamber outlet.

\subsection{CHORUS: an analytical model of acoustic propagation and generation of core-noise in a turbine}

CHORUS computes the acoustic propagation and generation of indirect combustion noise induced by non-homogeneous flows through turbine blades based on the actuator disk theory [8] recently revisited by Moreau and co-workers [6,19,42-44]. The flow can be considered two-dimensional, inviscid and isentropic in a blade-to-blade plane (blades heights are assumed small). Fluctuations of flow variables are assumed to be small compared with mean values: the conservation equations of mass, entropy and stagnation temperature through a stator. In the case of a rotor, stagnation temperature conservation is replaced by the rothalpy conservation. A last relation is given by Kutta's condition at the trailing edge of the blades. The set of resulting equations used in 
CHORUS reads

$\left(\frac{\dot{m}^{\prime}}{\dot{m}}\right)_{u}=\left(\frac{\dot{m}^{\prime}}{\dot{m}}\right)_{d}$

$\left(\frac{s^{\prime}}{c_{p}}\right)_{u}=\left(\frac{s^{\prime}}{c_{p}}\right)_{d}$

$\left(\frac{T_{t}^{\prime}}{T_{t}}\right)_{u}=\left(\frac{T_{t}^{\prime}}{T_{t}}\right)_{d}$

$\left(\theta^{\prime}\right)_{u}=\beta\left(\theta^{\prime}\right)_{d}$

for a stator and

$\left(\frac{\dot{m}^{\prime}}{\dot{m}}\right)_{u}=\left(\frac{\dot{m}^{\prime}}{\dot{m}}\right)_{d}$

$\left(\frac{s^{\prime}}{c_{p}}\right)_{u}=\left(\frac{s^{\prime}}{c_{p}}\right)_{d}$

$\left(\frac{I_{t}^{\prime}}{I_{t}}\right)_{u}=\left(\frac{I_{t}^{\prime}}{I_{t}}\right)_{d}$

$\left(\theta^{\prime}\right)_{u}=\beta\left(\theta^{\prime}\right)_{d}$

for a rotor. These jump conditions can be written in terms of the fluctuations of the primitive variables:

$\left(\frac{\dot{m}^{\prime}}{\dot{m}}\right)=\frac{p^{\prime}}{\gamma p}+\frac{1}{M} \frac{w^{\prime}}{c}-\theta^{\prime} \tan \theta$

$\left(\frac{T_{t}^{\prime}}{T_{t}}\right)=\frac{1}{1+\frac{(\gamma-1)}{2} M^{2}}\left[(\gamma-1) \frac{p^{\prime}}{\gamma p}+\frac{s^{\prime}}{c_{p}}+(\gamma-1) M \frac{w^{\prime}}{c}\right]$

$\left(\frac{I_{t}^{\prime}}{I_{t}}\right)=\frac{1}{1-\zeta}\left[\frac{T_{t}^{\prime}}{T_{t}}-\zeta\left(\frac{1}{M} \frac{w^{\prime}}{c}+\frac{\theta^{\prime}}{\tan \theta}\right)\right]$

where $\zeta=\frac{U v}{h_{t}}$. Thus, these equations can be written in a matrix form. For a row $i$ :

$\left[\epsilon_{u}^{i}\right]\left(\begin{array}{c}s^{\prime} / C_{p} \\ w^{\prime} / c \\ p^{\prime} / \gamma p \\ \theta^{\prime}\end{array}\right)_{u}^{i}=\left[\epsilon_{d}^{i}\right]\left(\begin{array}{c}s^{\prime} / C_{p} \\ w^{\prime} / c \\ p^{\prime} / \gamma p \\ \theta^{\prime}\end{array}\right)_{d}^{i}$

where $\left[\epsilon^{i}\right]$ is

$$
\begin{aligned}
{\left[\epsilon^{i}\right] } & =\left(\begin{array}{cccc}
1 & 0 & 0 & 0 \\
-1 & \frac{1}{M_{i}} & 1 & -\tan \theta_{i} \\
\frac{\mu_{i}}{\gamma-1} & \mu_{i} M_{i} & \mu_{i} & 0 \\
0 & 0 & 0 & \beta_{i}
\end{array}\right), \\
\mu_{i} & =\left(1+\frac{\gamma-1}{2} M_{i}^{2}\right) \text { and } M_{i}=\frac{w_{i}}{c_{i}}
\end{aligned}
$$

Using the matrix $\mathbf{K}^{i}$ defined in Eq. (10), the matrix product, Eq. (24), becomes

$$
\left[\epsilon_{u}^{i}\right]\left[\mathbf{K}_{u}^{i}\right]\left(\begin{array}{c}
\mathbf{w}_{s} \\
\mathbf{w}_{v} \\
\mathbf{w}_{+} \\
\mathbf{w}_{-}
\end{array}\right)_{u}=\left[\epsilon_{d}^{i}\right]\left[\mathbf{K}_{d}^{i}\right]\left(\begin{array}{c}
\mathbf{w}_{s} \\
\mathbf{w}_{v} \\
\mathbf{w}_{+} \\
\mathbf{w}_{-}
\end{array}\right)_{d}^{i},
$$

$\left[\mathbf{T}_{u}^{i}\right] \mathbf{W}_{u}^{i}=\left[\mathbf{T}_{d}^{i}\right] \mathbf{W}_{d}^{i}$ with $\left[\mathbf{T}^{i}\right]=\left[\epsilon^{i}\right]\left[\mathbf{K}^{i}\right]$ and $\mathbf{W}^{i}=\left(\begin{array}{c}\mathbf{w}_{s} \\ \mathbf{w}_{v} \\ \mathbf{w}_{+} \\ \mathbf{w}_{-}\end{array}\right)^{i}$
Note finally that to take into account the fact that wave propagation occurs between the rows of the turbine, phase shifts based on the wave travel times between rows are computed. Even though stators and rotors are assumed to be compact, these travel times between rotors and stators make the formulation frequency dependent. The combination of consecutive blade rows leads to matrix product giving a transfer function for each computed wave. For the case of multiple blade rows, the phase-shift of the waves through the blade-row spacing is taken into account. This is done using the matrix [S], in which the diagonal terms are the phase-shift of the waves, namely

$$
\left[\mathbf{S}^{i}\right]=\left(\begin{array}{cccc}
\exp \left(-i k_{x}^{S} L_{i}\right) & 0 & 0 & 0 \\
0 & \exp \left(-i k_{x}^{v} L_{i}\right) & 0 & 0 \\
0 & 0 & \exp \left(-i k_{x}^{+} L_{i}\right) & 0 \\
0 & 0 & 0 & \exp \left(-i k_{x}^{-} L_{i}\right)
\end{array}\right)
$$

The downstream waves vector $\mathbf{W}_{d}^{i}$ is related to the following blade row through $\mathbf{W}_{u}^{i+1}=\left[\mathbf{S}^{i}\right] \mathbf{W}_{d}^{i}$. Combining the successive stages of the turbine, a relation between the inlet and the outlet waves of the turbine can be written in a matrix form, giving

$\left[\prod_{i=1}^{N_{s}-1}\left(\left[T_{u}^{i+1}\right]\left[S^{i}\right]\left[T_{d}^{i}\right]\right)\right]\left[T_{u}^{1}\right] \cdot \mathbf{W}_{u}^{1}=\left[T_{d}^{N_{s}}\right] \mathbf{W}_{d}^{N_{s}}$.

As a result, CHORUS allows discriminating noise generated by entropy, vorticity as well as acoustic waves propagated through any number of turbine stages. Finally, Welsh's periodogram is used to compute the power spectral density of the acoustic pressure at the outlet of any turbine stage that takes into account the convective terms [45].

CHORUS was validated on canonical test cases: twodimensional LES were first performed to mimic acoustic generation in a stator $[18,44]$ by plane entropy waves, and compared with the CHORUS method. Good agreement was found between analytical and computed acoustic transfer functions. Entropy to acoustic transfer functions was found to depend on the scattering of the normal entropy wave to higher-order modes through the stator because of a non-uniform convective velocity through the blade rows. Indeed, turbulence mixing induced by the turbine blades generates a planar wave distortion and a damping of entropy waves through the first stages and no more indirect noise generation in the last stages. To take into account this low-pass filter behavior of the turbine stages, a scaling function was implemented based on the characteristic pitch of a blade row. The impact of this transfer function on numerical predictions will be discussed in Section 4.2. Validations of acoustic and entropy transfer functions through a rotor and a stator-rotor configuration were addressed in $[19,43]$. Under the compact assumption, all these studies show the ability of the analytical method to predict acoustic generation through a complete turbine stage at low frequency. Comparisons with the present experimental database (Section 2) are provided in the following sections.

\section{CONOCHAIN results and discussion}

CONOCHAIN is applied here to the TEENI engine. Combustion LES results are first presented in Section 4.1, before describing CHORUS results for noise in Section 4.2.

\subsection{Combustion chamber LES results}

\subsubsection{Mean flow predictions}

The computed combustion chamber is shown in Fig. 9. Pressurized air is injected from the compressor through the air inlet in 


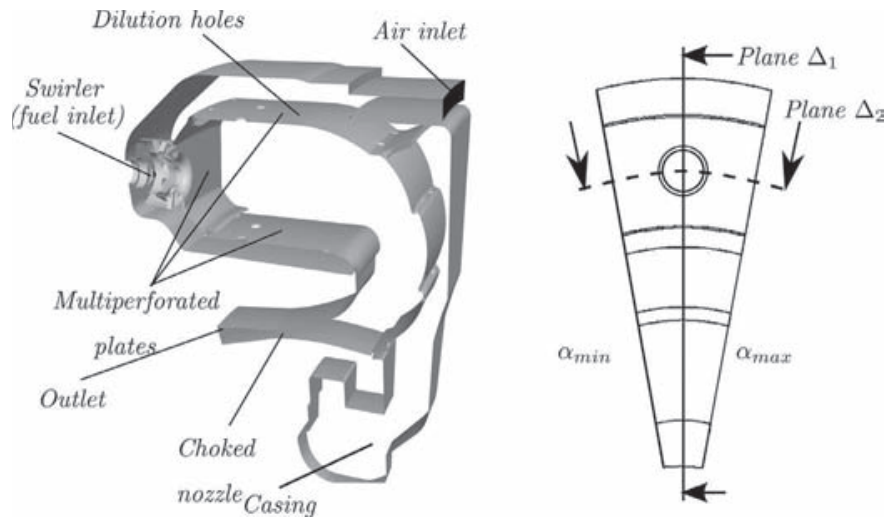

Fig. 9. Numerical domain for the LES and cutting planes locations over an axial section of the combustion chamber.

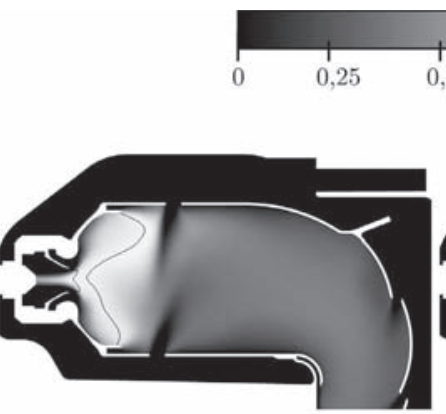

(a) Low power

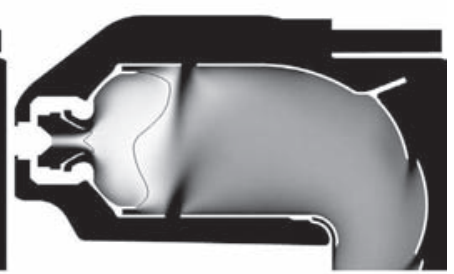

(b) High power
Fig. 10. Mean dimensionless temperature $\frac{T_{\text {mean }}-T_{\text {illet }}}{T_{\text {datiab }}-T_{\text {inlet }}}$ with an isoline of stoichiometric mixture fraction in plane $\Delta_{1}$ (Fig. 9).

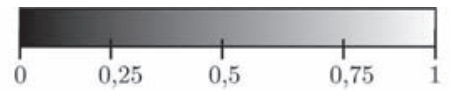

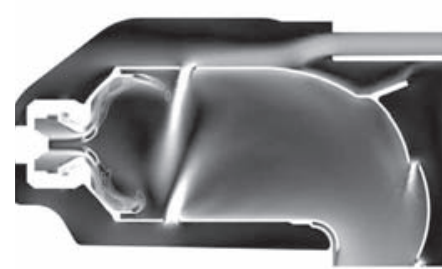

(a) Low power

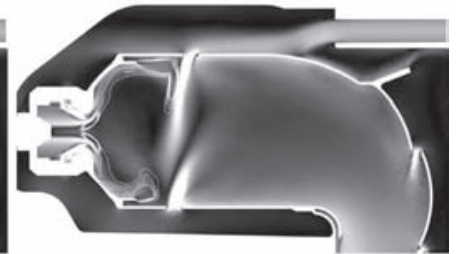

(b) High power
Fig. 11. Mean dimensionless velocity magnitude $\frac{u}{U_{\text {inlet }}}$ with white contours of mean heat release $\left(\mathrm{W} / \mathrm{m}^{3}\right)$ in plane $\Delta_{1}$ (Fig. 9).

the casing. In a real engine, liquid fuel is injected through injectors where it is atomized and vaporized. In these simulations, fuel is injected in gaseous phase close to the vaporizing zone at the lips of the injector. Taking into account the liquid spray of kerosene can impact the thermo-acoustic activity in Rich Quench Lean burners where evaporation and atomization characteristic times can modify the acoustic flame response [46,47]. Nevertheless, for these regimes, the atomization and the vaporization zones of the injected liquid fuel are very small and gaseous computations are sufficient to capture acoustic behavior of this combustion chamber [17]. Dilution holes ensure homogenization of burnt gases and a reduced mean temperature at the outlet of the combustion chamber. To ensure thermal wall protection, multi-perforated plates are positioned near the primary zone to generate local effusion cooling. Contrary to the dilution holes which are resolved, multi-perforated

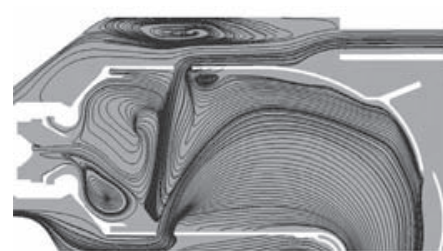

(a) Low power

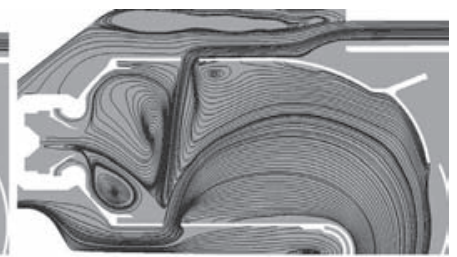

(b) High power
Fig. 12. Streamlines of the mean velocity vectors projected over the plane $\Delta_{1}$ (Fig. 9).

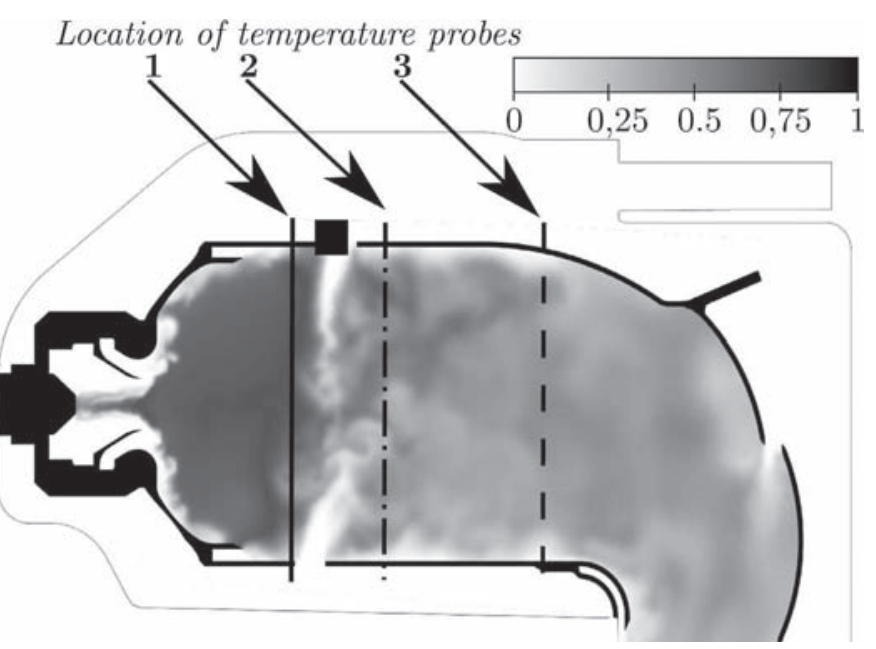

Fig. 13. Instantaneous dimensionless temperature field $\frac{T-T_{\text {inlet }}}{T_{\text {adiab }}-T_{\text {inlet }}}$ at high power in plane $\Delta_{1}$ (Fig. 9).

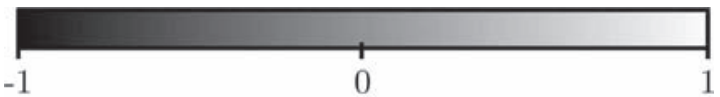

\section{Dilution holes}

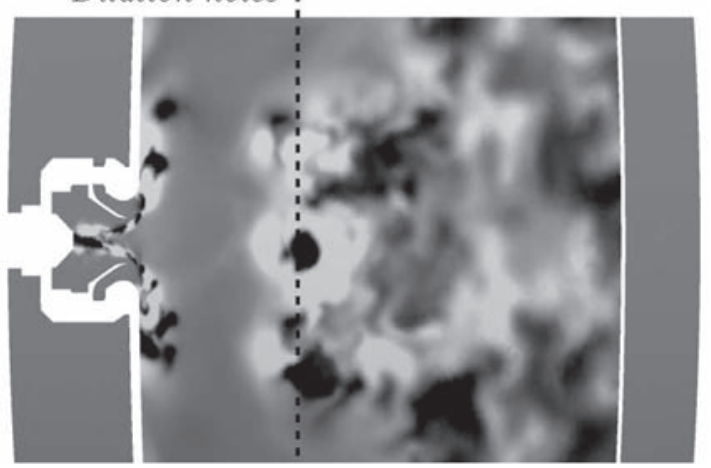

Fig. 14. Instantaneous dimensionless temperature fluctuation field $\frac{T-T_{\text {mean }}}{\max \left(T-T_{\text {men }}\right)}$ at high power in plane $\Delta_{2}$ (Fig. 9).

plates are modeled using a homogenized model that takes into account the mass flow rate across the plate [48]. Figure 10 shows the dimensionless mean temperature field (according to the inlet temperature in the combustion chamber and the stoichiometric adiabatic flame temperature at these regimes) for the two operating points (Table 1 ) in the meridional plane $\Delta_{1}$ (Fig. 9), with an isoline of stoichiometric fuel concentration. The variation of fuel-to-air ratio between these two simulations explains the difference of fuel and mean temperature distributions in the combustion chamber.

Figure 11 displays mean velocity fields (magnitude) for the low and high power cases: the mean velocity magnitudes are normalized by the mean inlet velocities which are identical in both cases. 


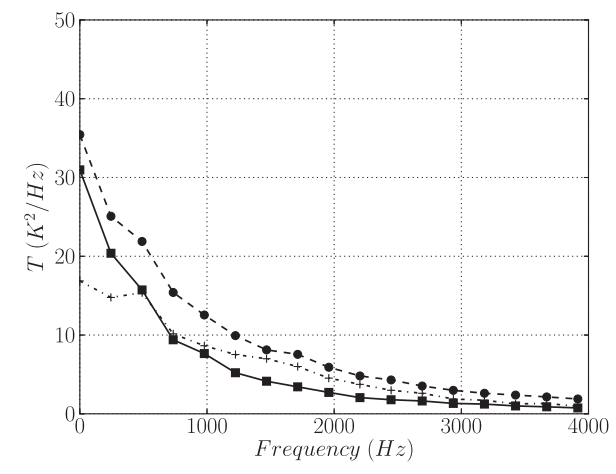

(a) Low power

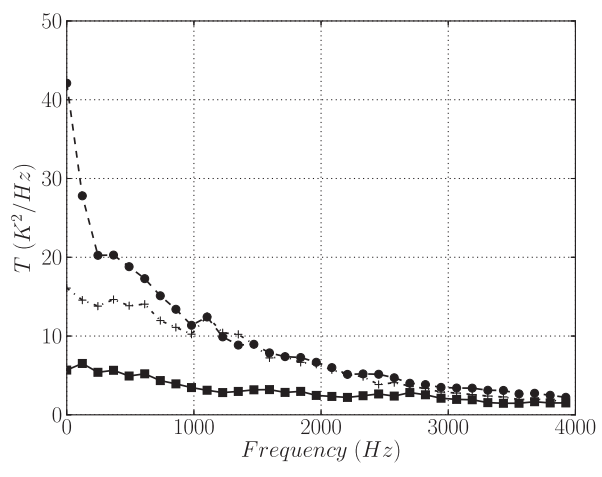

(b) High power

Fig. 15. Power spectral densities of unsteady temperature $\left(K^{2} / H z\right)$ in flame tube - plane $1(\mathbb{\square})$, plane $2(\bullet)$ and plane $3(+)$ in Fig. 13.

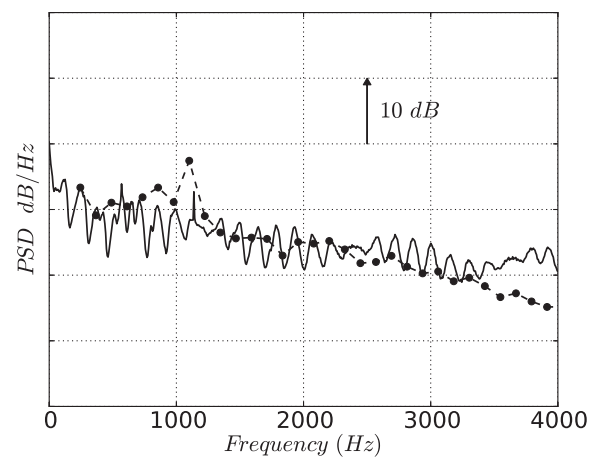

(a) Low power

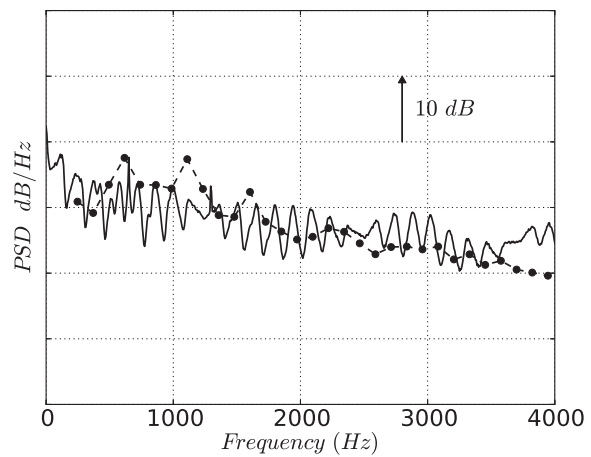

(b) High power

Fig. 16. Power spectral densities of pressure fluctuations (position A in Fig. 7) - LES (- - -) Experiment (— ).

The flame (visualized by white isolines of heat release) is stabilized at the swirler outlet in a low velocity recirculation zone induced by the swirling flow close to the lips of the swirler as well as by the dilution jet flows. The upper jet flow feeds the largest recirculation zone (Fig. 12) which leads to the slight asymmetry (with respect to injector axis) in the stoichiometric fuel fraction and the mean heat release. Spatial distributions of mean heat release in Fig. 11 show two main combustion regions, near the lips of the injector separator and close to the dilution holes. As expected, a larger and more spread-out heat release distribution is observed for the high power condition similarly to the isoline of stoichiometric fuel fraction.

\subsubsection{Unsteady activity in the combustor}

Combustion noise is due to the the acoustic waves generated by the unsteady heat release within the combustor (direct noise) and is also linked to the generation of entropy spots as well as vorticity waves (indirect noise). An unsteady analysis of LES results is therefore required before applying CHORUS.

Instantaneous dimensionless temperature fields are shown in Figs. 13 and 14 in a meridional plane $\Delta_{1}$ and a cylindrical plane $\Delta_{2}$ respectively. Both show significant temperature fluctuations generated by the turbulent combustion process and a strong stratification after the dilution holes with the formation of entropy spots. The largest temperature fluctuations occur in the second half of the flame tube where the dilution jets impact the gases leaving the primary zone. More quantitative results are obtained by the PSD of numerical temperature fluctuations over several planes defined in Fig. 13. The first plane is placed between the end of recirculation zone, the injector and the dilution holes while the second plane is located just after the dilution holes. Finally, a last plane is located before the flame tube starts turning. Fig. 10 showed that the mean

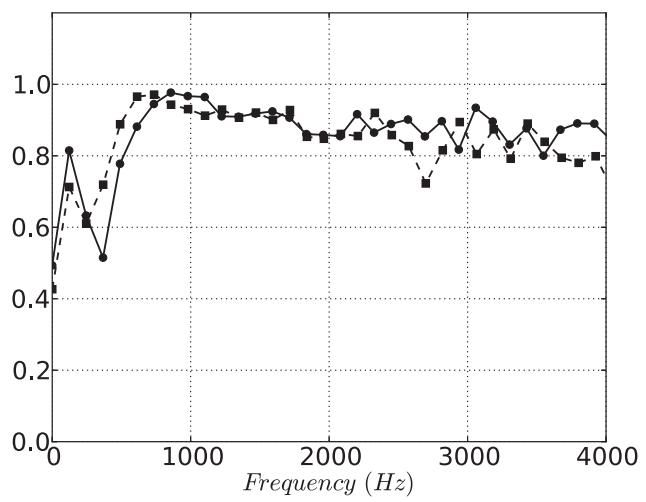

Fig. 17. Coherence signals between unsteady global heat release and a pressure probe at the outlet of the combustion chamber (plane $\mathbf{P}$ in Fig. 7) - low power $(---)$ and high power (

temperature decreases from the combustion zone to the exit of the flame tube. However, the PSD levels of the temperature fluctuations increase from the plane $\mathbf{1}$ to $\mathbf{2}$ more importantly for the high power case. Furthermore, RMS temperature levels show that temperature spots are mainly generated by the dilution and cooling devices of the combustion chamber, confirming the fields shown in Figs. 13 and 14. PSD levels found in plane $\mathbf{3}$ in both cases show that the amplitude of temperature fluctuations do not depend on the operating point for which the mean velocity field is not modified (Fig. 15).

PSD of numerical and experimental pressure fluctuations at location $\mathbf{A}$ in Fig. 9 are plotted in Fig. 16. The levels are well-predicted by the simulation for both power settings not only 


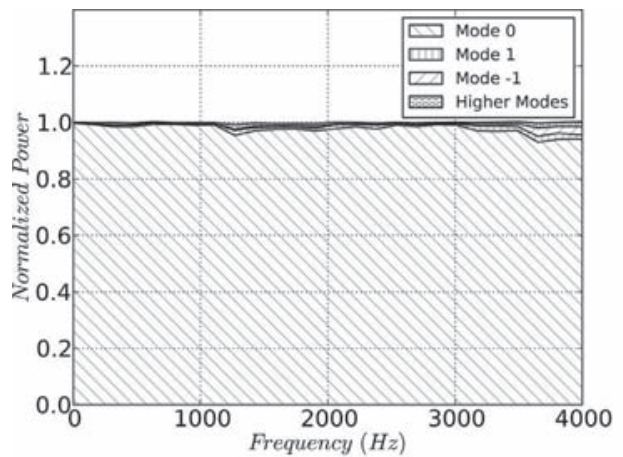

(a) Low power

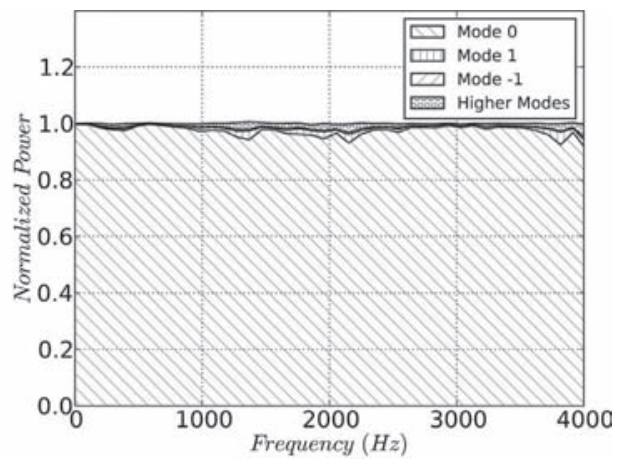

(b) High power

Fig. 18. Normalized modal PSD of pressure at the outlet of the combustion chamber (plane $\mathbf{P}$ in Fig. 7) using Eq. (9).

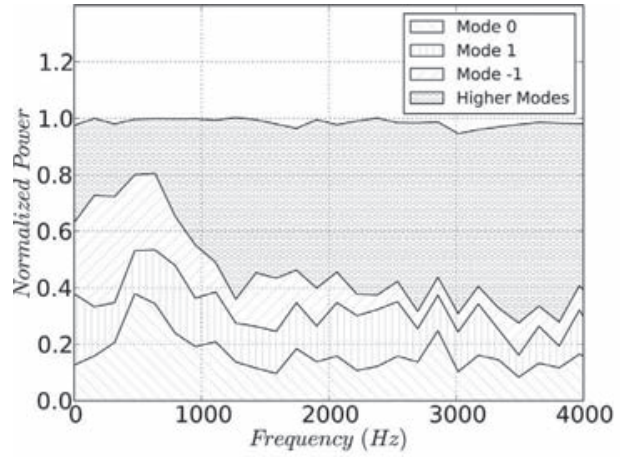

(a) Low power

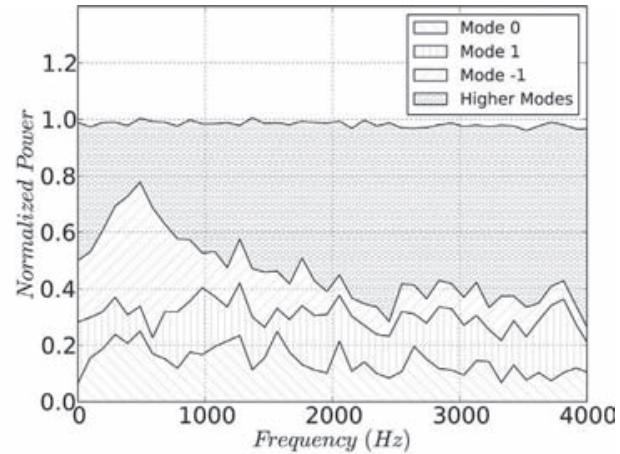

(b) High power

Fig. 19. Normalized modal PSD of entropy at the outlet of the combustion chamber (plane $\mathbf{P}$ in Fig. 7) using Eq. (9).

in magnitude but also in shape. The experimental oscillations are again caused by the response of the remote microphone probe as explained in the appendix. Note that there are very few examples of LES applied to real engine data and that Fig. 16 is one of the first quantitative demonstrations of LES capacities to predict noise within a real engine chamber.

Based on these LES, the dependence of the unsteady heat release on the combustor pressure fluctuations is highlighted by coherence spectra in Fig. 17 for the two operating conditions: as expected, wall pressure fluctuations are coupled with the global heat release in the chamber. Direct noise is dominant in the chamber.

\subsection{Combustion noise evaluation}

The CONOCHAIN method presented in Section 3.2 is now applied to the LES fields for the low and high power cases.

\subsubsection{CHORUS post-processing in the combustion chamber}

Low-frequency properties of combustion noise require LES to be computed for a long duration ( $80 \mathrm{~ms}$ ) as well as numerous instantaneous solutions to ensure an appropriate sampling frequency. For the CHORUS analysis, instantaneous flow solutions are extracted at a $50 \mathrm{kHz}$ sample rate to extract primitive variables over several outlet planes P (Fig. 7). A modal decomposition of the pressure or entropy fields over one plane (most downstream plane $\mathbf{P}$ in Fig. 7) at the outlet of the combustor is shown in Figs. 18 and 19, respectively.

As only one sector is computed, the first plane wave is sufficient to describe the pressure field. In contrast, the entropy field is a composition of several modes even if only the first planar mode will be considered in the following results. Indeed, the analytical

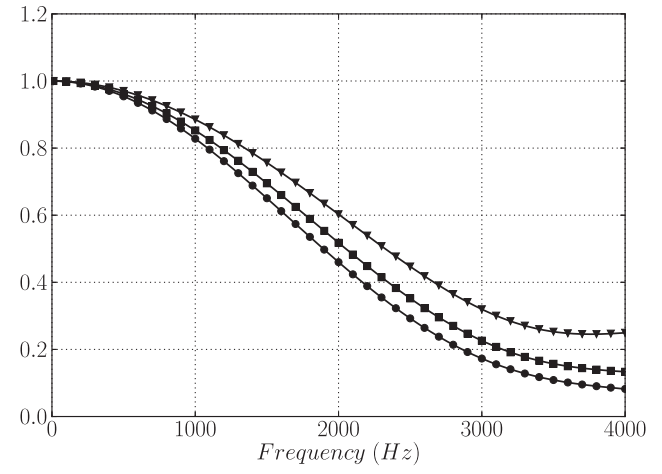

Fig. 20. Attenuation transfer function applied on entropy wave through the turbine at high power - position $\mathbf{B}($ ), position $\mathbf{C}(\boldsymbol{\square})$, and position $\mathbf{D}(\cdot)$ in Fig. 2.

model CHORUS is based on a mode-matching technique and the acoustic modes generated by the higher entropy modes cannot be propagated through the turbine stages because the first circumferential mode corresponds to the first multiple of the number of sector with a cut-off frequency out of the frequency range of interest. The difference of level close to $500 \mathrm{~Hz}$ between the energy carried by entropy modes 1 and -1 is found to be caused by the mean azimuthal velocity at the outlet of the combustion chamber, itself induced by the multi-perforated plates and the swirling flow motion in the flame tube.

The remaining part of this section deals with the PSD of acoustic pressure computed by the analytical method CHORUS at each experimental probe location and compared with experimental PSD. 


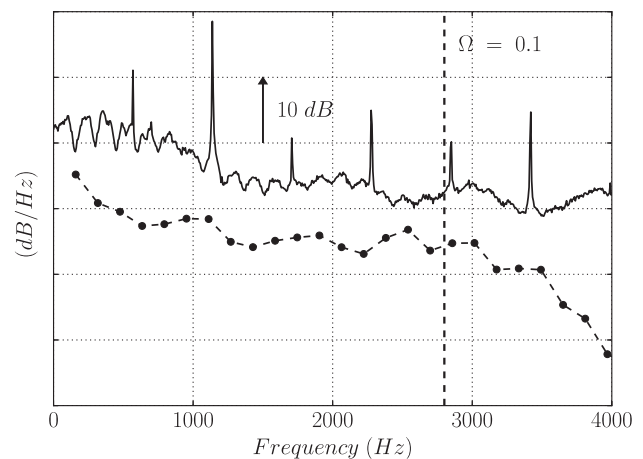

(a) Low power

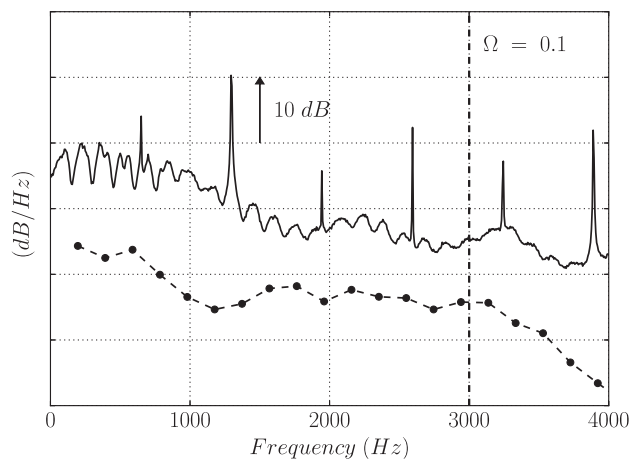

(b) High power

Fig. 21. Computed direct noise $(\bullet)$ and experimental PSD of pressure fluctuations ( $\_$) in the HPT position B in Fig. 2).

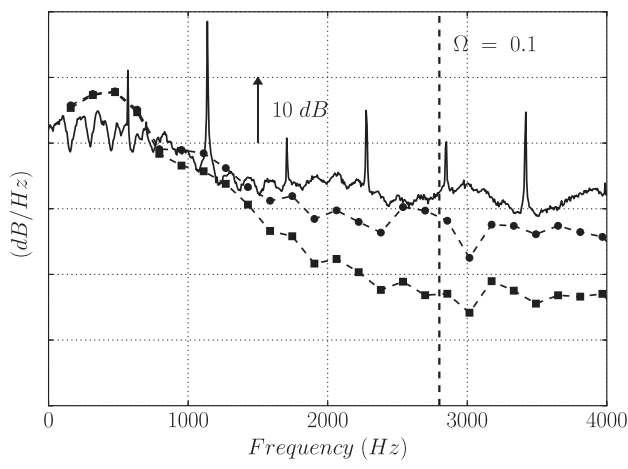

(a) Low power

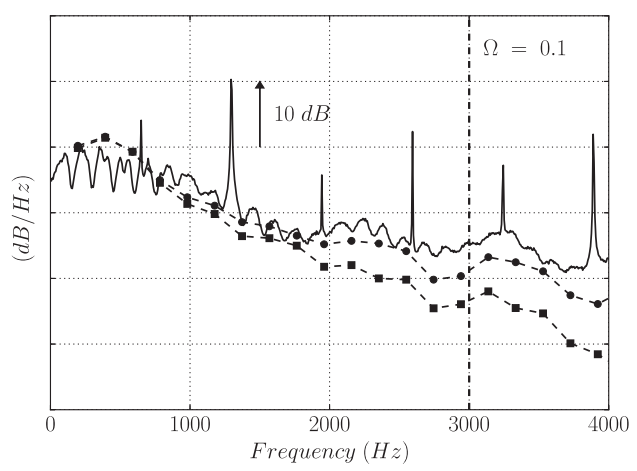

(b) High power

Fig. 22. Computed indirect noise with entropy conservation ( $\mathbf{\square})$ through the stage and without the attenuation function $(\bullet)$ and experimental PSD of pressure fluctuations $(\ldots)$ in the HPT (position B in Fig. 2).

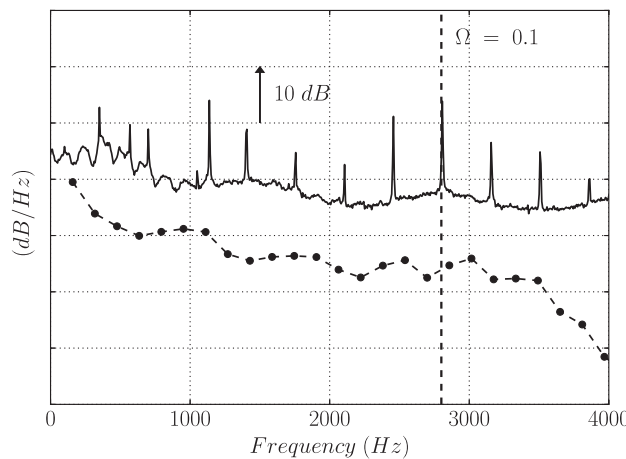

(a) Low power

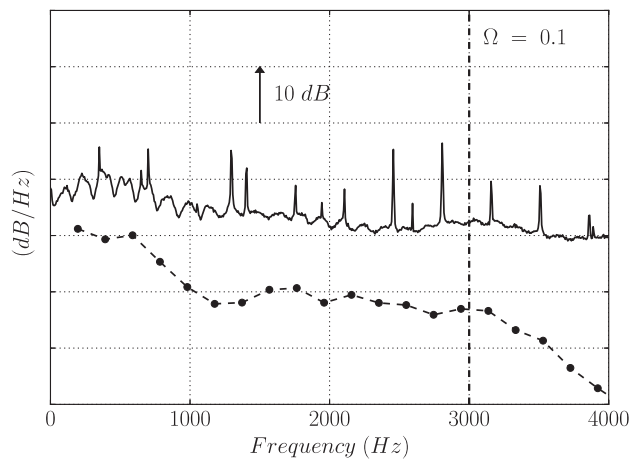

(b) High power

Fig. 23. Computed direct noise $(\bullet)$ and experimental PSD of pressure fluctuations $\left(\_\right.$) in the power turbine (position $\mathbf{C}$ in Fig. 2).

As indicated in Section 3.2, the attenuation of the entropy wave induced by the different turbine stages is taken into account with the transfer functions computed with the thermodynamic conditions encountered in the TEENI turbine and plotted in Fig. 20. Turbine rows are similar to low-pass filters and the increase of turbine stages leads to an important loss of entropy signal above $2000 \mathrm{~Hz}$. Indeed, the attenuation of plane entropy wave is a scattering process of energy into higher modes that it is not included in the disk actuator theory. Finally, scaling of each transfer function is based on a reference case corresponding to entropy wave propagation through a turbine stage $[6,19]$ at a given operating point based on the upstream mean velocity for each turbine row. For all these reasons, the large variations of thermodynamic conditions encountered in a real turbine can lead to slight differences between real attenuation transfer functions and the ones used in these computations.

\subsubsection{High pressure turbine}

Figure 21 shows the contribution of direct noise compared with the PSD levels of pressure fluctuations measured in the HPT (see Fig. 2). The compact assumption limits the comparison below $3000 \mathrm{~Hz}$ in the acoustic case $\left(\lambda>10 l_{c}\right.$ which corresponds to a reduced frequency $\Omega=\frac{l_{c}}{\lambda}<0.1$ ). Figure 21 confirms that the direct noise contribution to the overall noise in the turbine is small. A 


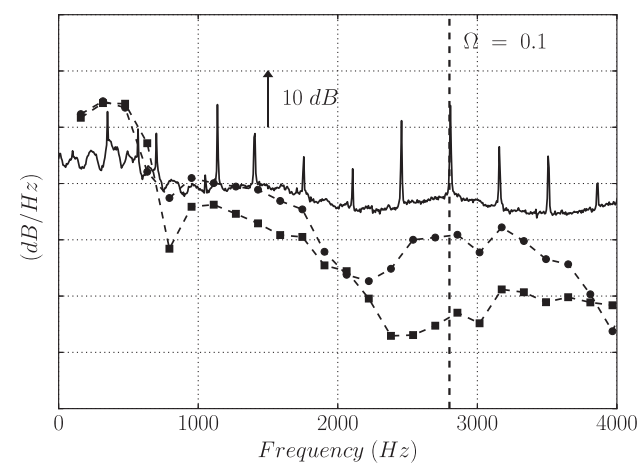

(a) Low power

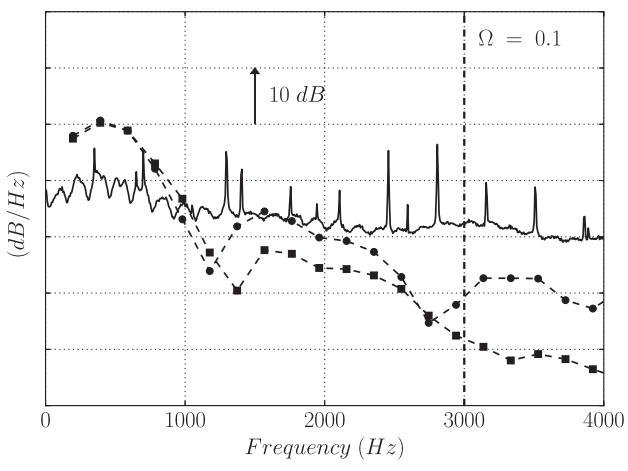

(b) High power

Fig. 24. Computed indirect noise with entropy conservation ( $\square$ ) through the stage and without the attenuation function $(\bullet)$ and experimental PSD of pressure fluctuations ( $($ ) in the power turbine (position $\mathbf{C}$ in Fig. 2).

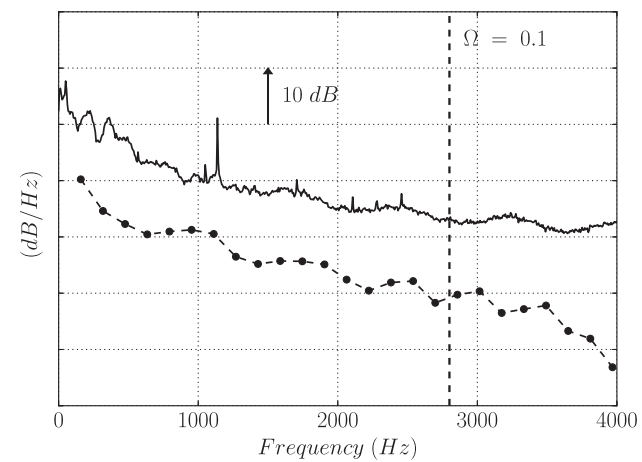

(a) Low power

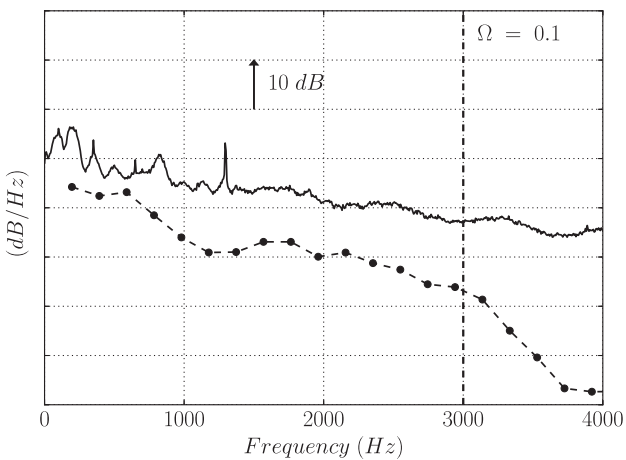

(b) High power

Fig. 25. Computed direct noise $(\bullet)$ and experimental PSD of pressure fluctuations ( $(-)$ ) in the exhaust (position D in Fig. 2).

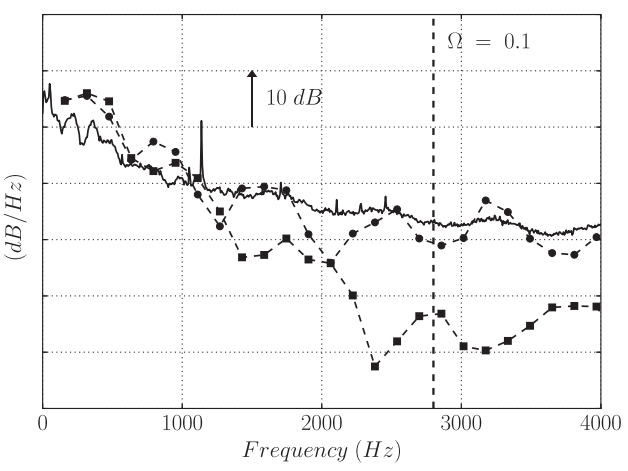

(a) Low power

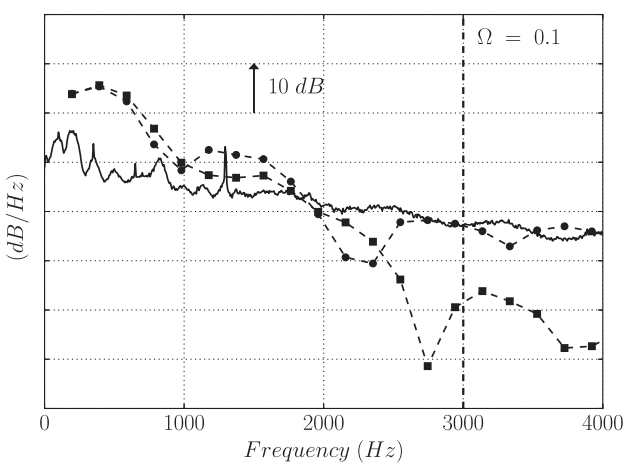

(b) High power

Fig. 26. Computed indirect noise with entropy conservation (

ש) through the stage and without the attenuation function $(\bullet)$ and experimental PSD of pressure fluctuations ( $($ ) in the exhaust (position D in Fig. 2).

weak contribution of vorticity waves to the indirect noise is found and consequently, only indirect noise induced by entropy waves is considered.

Figure 22 shows that the indirect noise generated by entropy waves going through the HPT stage is larger than direct noise even when an attenuation factor is used for entropy waves. Furthermore, the large experimental hump in PSD spectra at low frequency is correctly predicted both in terms of magnitude and pattern. Propagation of entropy waves through only two turbine rows did not show an important impact of the attenuation transfer function below $1000 \mathrm{~Hz}$ as suggested by the attenuation-transfer function plotted in Fig. 20. The predicted indirect noise humps are centered around $500 \mathrm{~Hz}$ where the entropy plane mode induced by the combustion chamber topology contribute the most (Fig. 19). Indirect noise is a major contributor to the total engine-radiated noise for this case. Furthermore, the low-frequency activity measured experimentally is correctly predicted both in terms of magnitude and pattern by CONOCHAIN.

\subsubsection{Power turbine}

As in the HPT, the direct noise predicted by CONOCHAIN is lower than the pressure fluctuations measured in the power turbine (Fig. 23). Computed indirect combustion is over-predicted by $6 \mathrm{~dB}$ in both cases (Fig. 24) below $1000 \mathrm{~Hz}$. Resonances between successive turbine rows can occur and yield these low-frequency humps. Above $1000 \mathrm{~Hz}$, the larger impact of the transfer function 


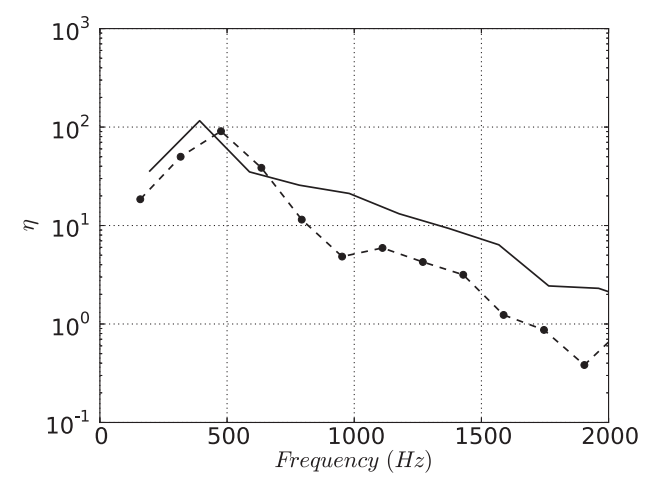

(a) High Pressure Turbine (B)

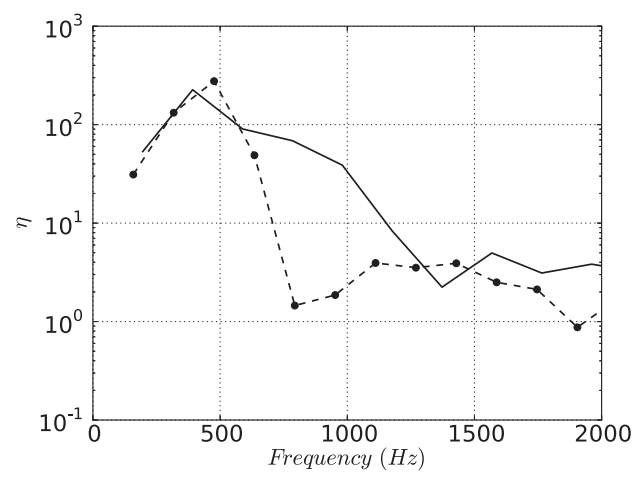

(b) Power turbine (C)

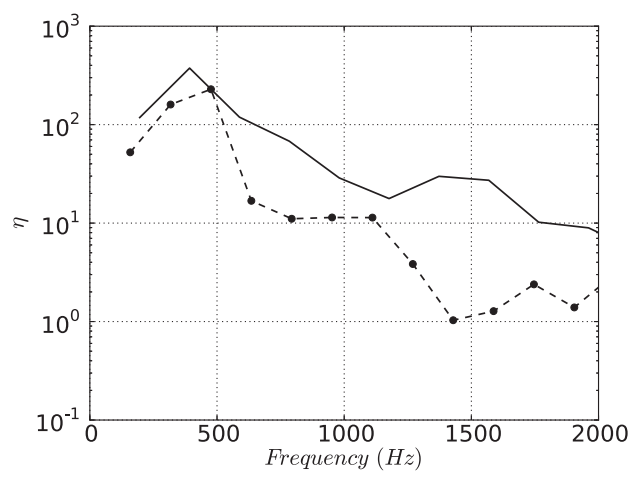

(c) Exhaust (D)

Fig. 27. Indirect to direct noise ratios $\eta$ at maximum power (__ $)$ and minimum power (- - -) measured in different locations within the engine.

of entropy attenuation on the computed PSD should be noted induced by the succession of turbine rows increases the scattering of the entropy planar mode.

\subsubsection{Exhaust}

At the exhaust, direct noise is definitely not an important contributor to the radiated total noise of the engine. The predicted magnitudes for direct noise in Fig. 25 are 5-10 dB lower than experimentally measured pressure fluctuations. The narrow-band experimental component found in the experiment at $200 \mathrm{~Hz}$ and attributed to the direct combustion noise is not present in the LES. By computing only a single sector of the annular combustion chamber, the acoustic field obtained with the LES is truncated which can explain the low levels of predicted direct combustion noise levels. Computed indirect noise with the entropy conservation through turbine stages is impacted by acoustic longitudinal resonances between the turbine rows in both cases (Fig. 26). At low power, computed indirect noise with the attenuation function matches the experimental PSD in the exhaust below $2000 \mathrm{~Hz}$ whereas computed indirect noise with the entropy wave conservation is $10 \mathrm{~dB}$ over-estimated. For the high power operating point, a slight difference occurs between computed indirect noise with the attenuation function and the experimental PSD below $1000 \mathrm{~Hz}$. As mentioned in the previous paragraph, this difference can be attributed to acoustic resonances within the turbine or an underpredicted attenuation of the entropy planar mode at very lowfrequency. For instance, the tone at $1100 \mathrm{~Hz}$ comes from turbines rotating shafts. Above $1500 \mathrm{~Hz}$, numerical results do not lie on the experimental values.

\subsection{Ratio of indirect noise to direct noise}

The ratios of indirect-to-direct noise in Fig. 27 emphasizes the importance of indirect noise in the overall radiated core-noise. For both power settings, the patterns are very similar. Indirect-todirect noise ratios below $2000 \mathrm{~Hz}$ is close to 10 in the HPT and the power turbine (Fig. 27(a) and (c)) and grows up to 100 in the exhaust. The slight difference in the exhaust (Fig. 27(c)) is mainly caused by different mean thermodynamic conditions in the turbine stages between the two operating points inducing different entropy planar mode scatterings.

\section{Conclusions}

The core-noise produced by a turboshaft engine has been investigated both experimentally and numerically within the European Project Framework TEENI.

Measurements in an actual turboshaft engine show for the first time that direct noise, generated by the acoustic activity within the combustion chamber and propagated through the turbine stages, corresponds to a narrowband peak close to $200 \mathrm{~Hz}$ in the overall radiated noise. Indirect core noise, induced by the acceleration of entropy and vorticity waves through the turbine stages, is mainly generated by the high-pressure turbine and characterized by a broadband hump up to $1500 \mathrm{~Hz}$.

In parallel, the CONOCHAIN methodology is applied to the actual experimental configuration to evaluate its ability to predict the combustion noise generated by a helicopter engine. Mechanisms responsible for combustion noise generation have been identified using full-gaseous reactive and turbulent LES of a single-sector of the annular combustion chamber. On the one hand, unsteady 
combustion due to flame oscillations in the first section of the combustion chamber is found to be the main source of pressure fluctuations in the combustor that are correctly predict by LES. It yields the direct combustion noise. On the other hand, entropy spots are mainly generated by dilution devices located further downstream the chamber primary zone without much acceleration. Nevertheless, computing only a single-sector of a combustion chamber can impact the acoustic activity where the acoustic longitudinal modes are dominant and the spatial decomposition of the flow variables at the combustor exit to feed the actuator disk theory for which only planar modes are considered.

The analytical model mimicking the combustion-noise generation within turbine stages and proposed by Cumpsty and Marble [8], further developed by Leyko in a stator vane [44] and numerically validated by Duran in a full turbine-stage cascade [43] is also applied to this actual engine and directly compared with experimental pressure fluctuations spectra for two operating points.

This coupled LES computation of the combustion chamber in the CONOCHAIN hybrid method shows the dominant role of indirect combustion noise in a turboshaft engine for the first time. Narrow-band contribution attributed to direct noise at $200 \mathrm{~Hz}$ in the experiment was not captured by LES in which predicted direct noise levels are found to be very low. Experimental broadband noise generation in the high-pressurized turbine can be related to entropy noise in the light of CONOCHAIN results. More generally, CONOCHAIN tool provides a reasonable estimation of broadband noise in the turbine stages below $1500 \mathrm{~Hz}$. The results also show the importance of entropy wave dispersion caused by turbine stages on the indirect combustion noise magnitude. Even if the transfer function applied to the entropy wave level to mimic this mechanism might not be well-adapted for the whole turbine, the conservation of entropy fluctuation through a row as proposed by Cumpsty and Marble [8] is not an acceptable assumption when several turbine stages are considered and yields significant overprediction of the indirect-to-direct noise ratio. A model for entropy waves attenuation is required. Finally, indirect noise induced by entropy waves is identified as a major contributor to the radiated core-noise below $1500 \mathrm{~Hz}$ contrary to direct noise which is found negligible.

\section{Acknowledgments}

The authors would like to thank Karsten Knobloch and Benjamin Pardowitz from the DLR for providing the TEENI internal data, GENCI (Grand Equipement National de Calcul Intensif) and IDRIS (Institut du Developpement et des Ressources en Informatique Scientifique) for providing part of the computing power necessary for these simulations. The support of ANRT/CIFRE is also acknowledged. This work was funded by Turbomeca.

\section{Appendix A. Analytical transfer function of experimental pressure probe in harsh conditions}

An analytical model to mimic the acoustic response of the experimental pressure probe used in the TEENI experiment is presented (Fig. 28). It is based on one-dimensional propagation in junction tubes [49] and is similar to what has been used for remote microphone probes in $[26,50,51]$.

\section{A.1. Sketch of the sensor}

The remote microphone is cooled by a controlled air flow injected from 3. The mass flow rate is set to ensure an efficient cooling and avoid noise generation. Along each pipe an $x$-coordinate with a positive direction outwards from $\mathbf{2}$ is defined.

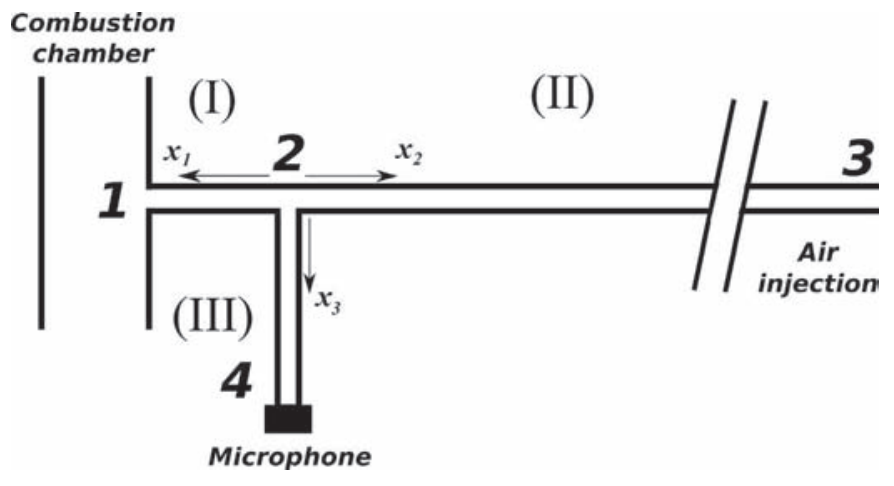

Fig. 28. Sketch of a pressure probe.

\section{A.2. Acoustic modeling}

No mean flow is considered in the sensor because the outlet 3 is closed. Mean temperature and mean pressure are assumed to be equal to the inlet combustion chamber values. Acoustic perturbations are supposed one-dimensional and harmonic. Thus, acoustic pressure fluctuation $p^{\prime}$ is written as

$p^{\prime}(x, t)=p^{+} e^{i\left(\omega t-k^{+} x\right)}+p^{-} e^{i\left(\omega t+k^{-} x\right)}$ with $k=\frac{\omega}{c_{0}}$

and the associated acoustic velocity fluctuation $u^{\prime}$ is

$u^{\prime}(x, t)=\frac{1}{\rho_{0} c}\left(p^{+} e^{i\left(\omega t-k^{+} x\right)}-p^{-} e^{i\left(\omega t+k^{-} x\right)}\right)$

The analytical transfer function is computed between the acoustic pressure in $\mathbf{4}$ and the acoustic pressure in $\mathbf{1}$. Closed ends are considered in $\mathbf{3}$ and $\mathbf{4}$ to set infinite acoustic impedances. In $\mathbf{2}$, a compact T-junction gives pressure and velocity jump conditions using mass and pressure conservation. These conditions provide a set of six equations

$p_{I}^{\prime}(0, t)=p_{I I}^{\prime}$

$p_{I}^{\prime}(0, t)=p_{I I I}^{\prime}$

$u_{I}^{\prime}(0, t) \cdot S_{I}+u_{I I}^{\prime}(0, t) \cdot S_{I I}+u_{I I I}^{\prime}(0, t) \cdot S_{I I I}=0$

$p_{I}^{\prime}\left(l_{I}, t\right)=1$

$p_{I I}^{\prime}\left(l_{I I}, t\right)=Z_{3} u_{I I}^{\prime}\left(l_{I I}, t\right)$

$p_{I I I}^{\prime}\left(l_{I I I}, t\right)=Z_{4} u_{I I I}^{\prime}\left(l_{I I I}, t\right)$.

Using the plane wave formulation in Eqs. (30), and (31)), the set of Eqs. (32)-(37) is expressed only with downstream and upstream acoustic waves. So, the system can be written in matrix form:

$M X=B$

where

$X=\left(\begin{array}{l}p_{I}^{+} \\ p_{I}^{-} \\ p_{I I}^{+} \\ p_{I I}^{-} \\ p_{I I}^{+} \\ p_{I I I}^{-}\end{array}\right)$and $B=\left(\begin{array}{l}1 \\ 0 \\ 0 \\ 0 \\ 0 \\ 0\end{array}\right)$ 


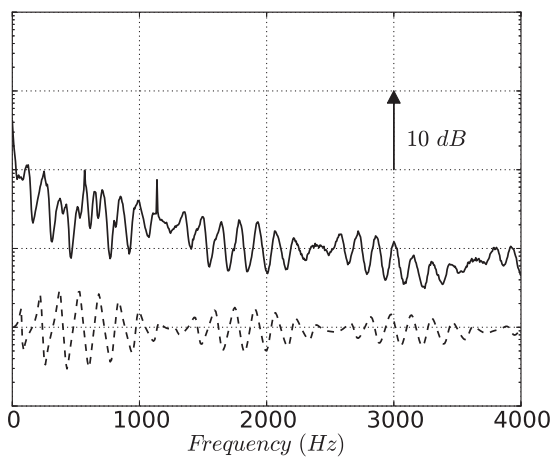

(a) Low power (A)

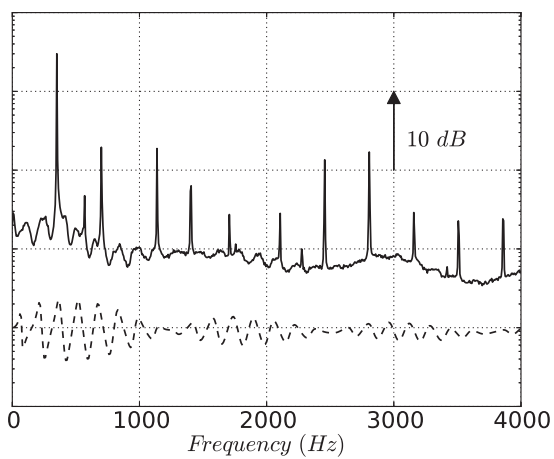

(c) Low power $(\mathbf{C})$

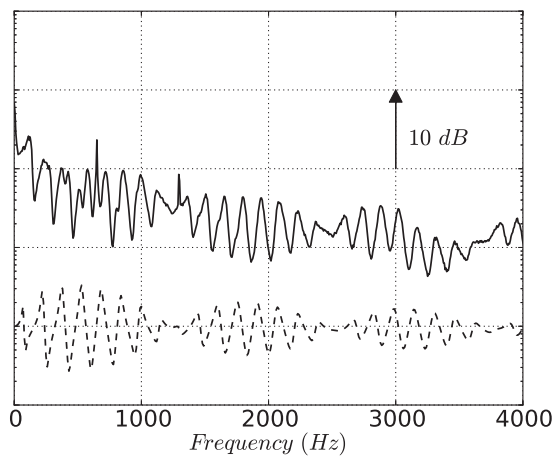

(b) High power $(\mathbf{A})$

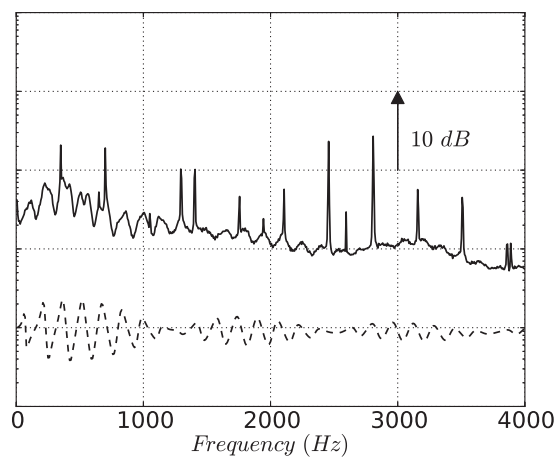

(d) High power (C)

Fig. 29. PSD of pressure fluctuations in the combustion chamber and the power turbine (positions $\mathbf{A}$ and $\mathbf{C}$ in Fig. 2 respectively) (_ $)$ ) and analytical transfer functions $(---)$.

and the matrix $M$ is

$$
\left(\begin{array}{ccccc}
1 & 1 & 0 & 0 & 0 \\
0 & 0 & 0 & 0 & e^{i\left(-k L_{I I I}\right)}\left(1-\frac{Z_{4}}{\rho_{0} c}\right) \\
0 & 0 & e^{i\left(-k L_{I I}\right)}\left(1-\frac{Z_{3}}{\rho_{0} c}\right) & e^{i\left(k L_{I I}\right)}\left(1+\frac{Z_{3}}{\rho_{0} c}\right) & 0 \\
1 & 1 & -1 & -1 & 0 \\
1 & 1 & 0 & 0 & -1 \\
S_{I} & -S_{I} & S_{I I} & -S_{I I} & S_{I I I}
\end{array}\right.
$$

Solving the system of equations gives directly the acoustic pressure fluctuation recorded by the microphone. However, this modeling is not sufficient to explain the acoustic resonance visible in the PSD of pressure fluctuations in Fig. 16(b) and (a) because the effect of kinematic viscosity, responsible for the ability of the probe to absorb standing waves within the sensor, is not taken into account. To do this, a modified wave number $k_{m}$

$k_{m}=\frac{1}{4}(1-i) \frac{L_{p}}{A} \sqrt{\frac{2 v_{0}}{\omega}} k\left(1+(\gamma-1) \frac{1}{\sqrt{\operatorname{Pr}}}\right)+k$

is used to introduce an imaginary part able to mimic damping effect of the kinematic viscosity, as proposed in [49] to consider acoustic damping within boundary layers. Note that the modified wave number defined in (41) tends to $k$ when the kinematic viscosity tends to zero.

Finally, several acoustic transfer functions are plotted in Fig. 29 for pressure probe mounted in the combustion chamber (position $\mathbf{A}$ in Fig. 2) and in the power turbine (position $\mathbf{C}$ in Fig. 2). Note that the mean pressure is higher in the combustion chamber for both power settings. Thus, damping effect in the sensors decreases with increasing pressure. Finally, the multiple peaks correspond to the maxima observed in the PSD of pressure in the combustion chamber (Fig. 3(a)), suggesting that the modulation observed on

$$
\left.\begin{array}{c}
0 \\
e^{i\left(k L_{I I I}\right)}\left(1+\frac{Z_{4}}{\rho_{0} c}\right) \\
0 \\
0 \\
-1 \\
-S_{I I I}
\end{array}\right)
$$

all experimental PSD is due to the transfer function of the pressure probes.

\section{References}

[1] S. Candel, Acoustic transmission and reflection by a shear discontinuity separating hot and cold regions, J. Sound Vib. 24 (1972) 87-91.

[2] F.E. Marble, S. Candel, Acoustic disturbances from gas nonuniformities convected through a nozzle, J. Sound Vib. 55 (1977) 225-243.

[3] F.E. Marble, J.E. Broadwell, The coherent flame model for turbulent chemical reactions, Project Squid Technical Report TRW-9-PU, Project Squid Headquarters, 1977.

[4] A.S. Morgans, S.R. Stow, Model-based control of combustion instabilities in annular combustors, Combust. Flame 150 (4) (2007) 380-399.

[5] A. Giauque, M. Huet, F. Clero, Analytical analysis of indirect combustion noise in subcritical nozzles, in: ASME Turbo Expo, x, 2012, pp. 1-16.

[6] I. Duran, S. Moreau, Numerical simulation of acoustic and entropy waves propagating through turbine blades, 19th AIAA/CEAS Aeroacoustics Conference (34th AIAA Aeroacoustics Conference), AIAA2013-2102 Paper, Berlin, Germany, (2013).

[7] W. Moase, M. Brear, C. Manzie, The forced response of choked nozzles and supersonic diffusers, J. Fluid Mech. 585 (2007) 281-304

[8] N.A. Cumpsty, F.E. Marble, The interaction of entropy fluctuations with turbine blade rows; a mechanism of turbojet engine noise, Proc. R. Soc. Lond. A 357 (1977) 323-344. 
[9] G.F. Pickett, Core engine noise due to temperature fluctuations convecting through turbine blade rows, 2nd AIAA Aeroacoustics Conference, AIAA Paper 1975-528, (1975).

[10] V.L. Doyle, R.K. Matta, Attenuation of upstream-generated low frequency noise by gas turbines, Technical Report CR-135219, NASA, 1977.

[11] L. Gicquel, G. Staffelbach, T. Poinsot, Large eddy simulations of gaseous flames in gas turbine combustion chambers, Prog. Energy Combust. Sci. 38 (6) (2012) 782-817.

[12] P. Moin, S.V. Apte, Large-eddy simulation of realistic gas turbine combustors, AIAA J. 44 (4) (2006) 698-708.

[13] K. Mahesh, G. Constantinescu, S. Apte, G. Iaccarino, F. Ham, P. Moin, Large eddy simulation of reacting turbulent flows in complex geometries, ASME J. Appl. Mech. 73 (2006) 374-381.

[14] C. Fureby, LES of a multi-burner annular gas turbine combustor, Flow Turbul. Combust. 84 (2010) 543-564

[15] G. Kuenne, A. Ketelheun, J. Janicka, LES modeling of premixed combustion using a thickened flame approach coupled with FGM tabulated chemistry, Combust. Flame 158 (9) (2011) 1750-1767.

[16] S. Roux, M. Cazalens, T. Poinsot, Influence of outlet boundary condition for large eddy simulation of combustion instabilities in gas turbine, J. Propul. Power 24 (3) (2008) 541-546.

[17] P. Wolf, G. Staffelbach, A. Roux, L Gicquel, T. Poinsot, V Moureau, Massively parallel LES of azimuthal thermo-acoustic instabilities in annular gas turbines, C. R. Acad. Sci. Méc. 337 (6-7) (2009) 385-394.

[18] M. Leyko, S. Moreau, F. Nicoud, T. Poinsot, Waves transmission and generation in turbine stages in a combustion-noise framework, 16th AIAA/CEAS AeroAcoustics Conference, (2010).

[19] I. Duran, S. Moreau, Study of the attenuation of waves propagating through fixed and rotating turbine blades, 18th AIAA/CEAS Aeroacoustics Conference (33rd AIAA Aeroacoustics Conference), AIAA 2012-2133 paper, (2012).

[20] A. Mishra, D.J. Bodony, Evaluation of actuator disk theory for predicting indirect combustion noise, J. Sound Vib. 332 (4) (2013) 821-838.

[21] F. Bake, N. Kings, A. Fischer, R. I., Experimental investigation of the entropy noise mechanism in aero-engines, Int. J. Aeroacoust. 8 (1-2) (2008) 125-142.

[22] F. Bake, C. Richter, B. Muhlbauer, N. Kings, I. Rohle, F. Thiele, B. Noll, The entropy wave generator (EWG): a reference case on entropy noise, J. Sound Vib. (2009) 574-598

[23] B. Muhlbauer, B. Noll, M. Aigner, Numerical investigation of the fundamental mechanism for entropy noise generation in aero-engines, Acta Acust. United Acust. 95 (2009) 470-478.

[24] A. Giauque, M. Huet, F. Clero, Analytical analysis of indirect combustion noise in subcritical nozzles, J. Eng. Gas Turb. Power 134 (11) (2012) 111202.

[25] M. Leyko, F. Nicoud, S. Moreau, T. Poinsot, Numerical and analytical investigation of the indirect noise in a nozzle, in: Summer Program, Center for Turbulence Research, NASA AMES, Stanford University, USA, 2008, pp. 343-354.

[26] S. Perennes, M. Roger, Aerodynamic noise of a two-dimensional wing with high-lift devices, 4th AIAA/CEAS Aeroacoustics Conference, AIAA Paper 982338, (1998)

[27] F. Bake, U. Michel, I. Roehle, Investigation of entropy noise in aero-engine combustors, J. Eng. Gas Turb. Power 129 (2) (2007) 370-376.

[28] J.Y. Chung, Rejection of flow noise using a coherence function method, J. Acoust. Soc. Am. 62 (2) (1977) 388-395.

[29] E.A. Krejsa, Combustion noise from gas turbine aircraft engines measurement of far-field levels, Technical Report NASA Technical Report 88971, NASA, 1987.

30] B.N. Shivashankara, Gas turbine core noise source isolation by internal-to-farfield correlations, J. Aircr. 15 (9) (1978) 597-600.
[31] P.H. Wirsching, T.L. Paez, K. Ortiz, Random vibrations: theory and practice, Dover Publications, 2006.

[32] J. Kopitz, E. Brocker, W. Polifke, Characteristics-based filter for identification of planar acoustic waves in numerical simulation of turbulent compressible flow, in: 12th International Congress on Sound and Vibration, 2005.

[33] AVBP, AVBP code: http://www.cerfacs.fr/cfd/avbp_code.php and http://www. cerfacs.fr/cfd/cfdpublications.html.

[34] O. Colin, M. Rudgyard, Development of high-order Taylor-Galerkin schemes for unsteady calculations, J. Comput. Phys. 162 (2) (2000) 338-371.

[35] J. Smagorinsky, General circulation experiments with the primitive equations. 1. The basic experiment., Mon. Weather Rev. 91 (1963) 99-164.

[36] O. Colin, F. Ducros, D. Veynante, T. Poinsot, A thickened flame model for large eddy simulations of turbulent premixed combustion, Phys. Fluids 12 (7) (2000) 1843-1863.

[37] L. Selle, G. Lartigue, T. Poinsot, R. Koch, K.-U. Schildmacher, W. Krebs, B. Prade, P. Kaufmann, D. Veynante, Compressible large-eddy simulation of turbulent combustion in complex geometry on unstructured meshes, Combust. Flame 137 (4) (2004) 489-505.

[38] T. Poinsot, D. Veynante, Theoretical and numerical combustion, third edition, 2011 www.cerfacs.fr/elearning.

[39] B. Franzelli, E. Riber, M. Sanjosé, T. Poinsot, A two-step chemical scheme for large-eddy simulation of kerosene-air flames, Combust. Flame 157 (7) (2010) 1364-1373.

[40] T. Poinsot, S. Lele, Boundary conditions for direct simulations of compressible viscous flows, J. Comput. Phys. 101 (1) (1992) 104-129.

[41] L. Selle, F. Nicoud, T. Poinsot, The actual impedance of non-reflecting boundary conditions: implications for the computation of resonators, AIAA J. 42 (5) (2004) 958-964

[42] I. Duran, M. Leyko, S. Moreau, F. Nicoud, T. Poinsot, Computing combustion noise by combining large eddy simulations with analytical models for the propagation of waves through turbine blades, 3rd Colloquium INCA, Toulouse, France, (2011).

[43] I. Duran, M. Leyko, S. Moreau, F. Nicoud, T. Poinsot, Computing combustion noise by combining large eddy simulations with analytical models for the propagation of waves through turbine blades, C. R. Acad. Sci. 341 (1-2) (2013) 131-140.

[44] M. Leyko, I. Duran, S. Moreau, F. Nicoud, T. Poinsot, Simulation and modelling of the waves transmission and generation in a stator blade row in a combustion-noise framework, J. Sound Vib. 333 (23) (2014) 6090-6106.

[45] F.P. Bretherton, C.J.R. Garrett, Wavetrains in inhomogeneous moving media, Proc. R. Soc. Lond. 302 (1471) (1968) 529-554.

[46] P. Gajan, A. Strzelecki, B. Platet, R. Lecourt, F. Giuliani, Investigation of spray behavior downstream of an aeroengine injector with acoustic excitation, J. Propuls. Power 23 (2) (2007) 390-397.

[47] M. De la Cruz Garcia, E. Mastorakos, A. Dowling, Investigations on the selfexcited oscillations in a kerosene spray flame, Combust. Flame 156 (2) (2009) 374-384.

[48] S. Mendez, J. Eldredge, Acoustic modeling of perforated plates with bias flow for large-eddy simulations, J. Comput. Phys. 228 (13) (2009) 4757-4772.

[49] S.W. Rienstra, A. Hirschberg, An introduction to acoustics No. 2011, Eindhoven University of Technology, 2011.

[50] S. Moreau, M. Roger, Effect of airfoil aerodynamic loading on trailing edge noise sources, AIAA J. 43 (7) (2005) 41-52.

[51] A. Chauvin, M. Sanjose, G. Lobel, S. Moreau, M. Brouillette, Experimental and numerical investigation on noise induced by a butterfly valve, 20th AIAA/CEAS Aeroacoustics Conference, (June 2014) 